\title{
Nanoscale Effects in Water Splitting Photocatalysis
}

\author{
Frank E. Osterloh
}

\begin{abstract}
From a conceptual standpoint, the water photoelectrolysis reaction is the simplest way to convert solar energy into fuel. It is widely believed that nanostructured photocatalysts can improve the efficiency of the process and lower the costs. Indeed, nanostructured light absorbers have several advantages over traditional materials. This includes shorter charge transport pathways and larger redox active surface areas. It is also possible to adjust the energetics of small particles via the quantum size effect or with adsorbed ions. At the same time, nanostructured absorbers have significant disadvantages over conventional ones. The larger surface area promotes defect recombination and reduces the photovoltage that can be drawn from the absorber. The smaller size of the particles also makes electron-hole separation more difficult to achieve. This chapter discusses these issues using selected examples from the literature and from the laboratory of the author.
\end{abstract}

Keywords Fermi Level • Junction - Metal Oxide • Recombination • Surface Photovoltage

\section{Contents}

1 Photoelectrochemical Water Splitting as a Pathway to Sustainable Energy

2 Brief History of Nanoscale Water Splitting Photocatalysis

3 Size Dependency of Free Energy Creation in Photocatalysts

4 Light Absorption

5 Majority and Minority Carrier Transport

6 Quantum Size Confinement

7 Multiple Exciton Generation

8 Ion Effects

9 Interfacial Charge Transfer

\author{
F.E. Osterloh $(\bowtie)$ \\ Department of Chemistry, University of California, Davis, CA 95616, USA \\ e-mail: fosterloh@ucdavis.edu
}


10 Electron-Hole Recombination

11 Excited State Entropy

12 Electron-Hole Separation

13 Interparticle Charge Transport

14 Examples of Nanoscale Photocatalysts for Overall Water Splitting

15 Measuring Photovoltage in Nanoscale Photocatalysts

16 Conclusion

References

\section{Photoelectrochemical Water Splitting as a Pathway to Sustainable Energy}

The goal of keeping global temperature increases below $2^{\circ} \mathrm{C}$ compared to pre-industrial times requires the rapid deployment of carbon free energy technology that can compete with the price of fossil fuels. The solar energy received on the Earth's surface meets current and future human energy demand [1,2]. Solar energy can be converted into electricity with up to $46 \%$ efficiency using the photovoltaic cells that are available today [3]. However, electricity is difficult to store and distribute over long distances. These problems can be avoided by converting the photochemical energy directly into fuel. The simplest scheme employs the photoelectrolysis reaction shown in (1) to produce hydrogen from water:

$$
\mathrm{H}_{2} \mathrm{O} \rightarrow 1 / 2 \mathrm{O}_{2(\mathrm{~g})}+\mathrm{H}_{2}(\mathrm{~g}) ; \quad \Delta G=+237 \mathrm{~kJ} / \mathrm{mol} .
$$

Hydrogen from this reaction could become the central energy carrier of a hydrogenbased economy [2]. Alternatively, it could be used as an electron source for the exothermic formation of conventional fuels using atmospheric $\mathrm{CO}_{2}$ as a carbon feedstock. The technology for creating hydrogen by oxidation of water (solar water splitting) already exists in the form of multi-junction photovoltaic systems coupled to water electrolyzers. These can achieve over $18 \%$ energy efficiency [4] but they are so expensive that nobody uses them - especially not anyone living on less than $\$ 10$ a day, i.e., the majority of people in the world [5, 6]. Photovoltaics based on lead iodide perovskite might be a promising alternative [7] if problems with photoand thermal stability, scaling, and lead toxicity can be resolved [8]. Potential cost savings are also possible with photoelectrochemical cells (PEC) that combine photovoltaic and electrolytic functions in one unit (Fig. 1) [9]. PECs can reach efficiencies of up to $12.4 \%$ [10], about half of the theoretical efficiency limit for these devices $(24.4 \%$ for a tandem $[11,12]$ and $30 \%$ for a multijunction device [4]). However, issues with stability continue to plague these devices $[13,14]$.

Of all known solar hydrogen technologies, solar water electrolysis with suspended photocatalysts (PCs) has the greatest potential to induce a revolution in fuel production on this planet. Photocatalysts generate hydrogen and oxygen upon exposure of a particle-water mixture to sunlight (Fig. 2a) [15-24]. Because of the total integration of components for light absorption, charge separation, and 


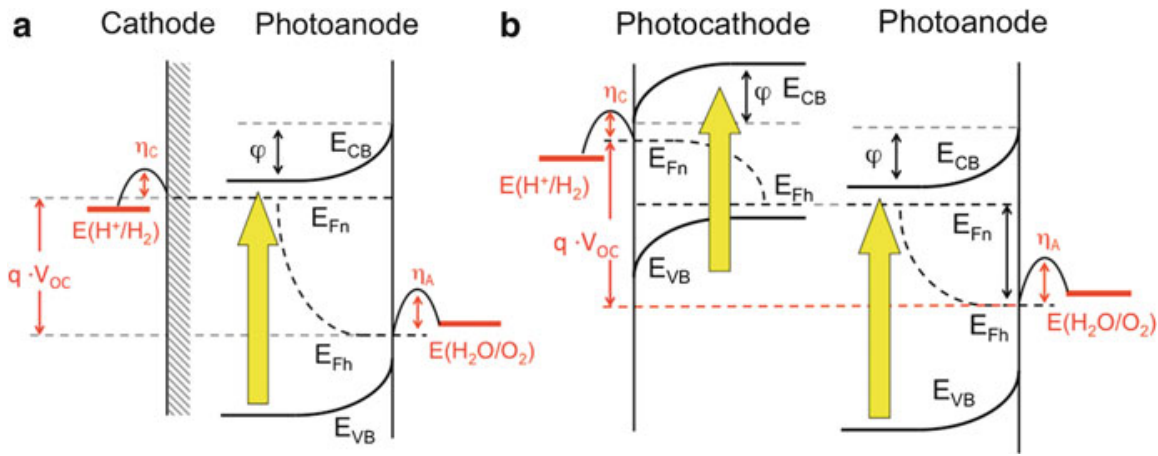

Fig. 1 Energetics of (a) type 1 (single absorber) and (b) type 2 (dual absorber, tandem) suspended photocatalysts for water photoelectrolysis. For photochemical water splitting, the quasi Fermi levels $E_{\mathrm{Fn}}$ and $E_{\mathrm{Fh}}$ of the illuminated catalysts need to be above and below the water redox potentials. Band bending $\varphi$, maximum possible energy output $\left(q \times V_{\mathrm{OC}}\right)$, and electrochemical overpotentials for anodic $\eta_{\mathrm{A}}$ and cathodic $\eta_{\mathrm{C}}$ processes are also shown

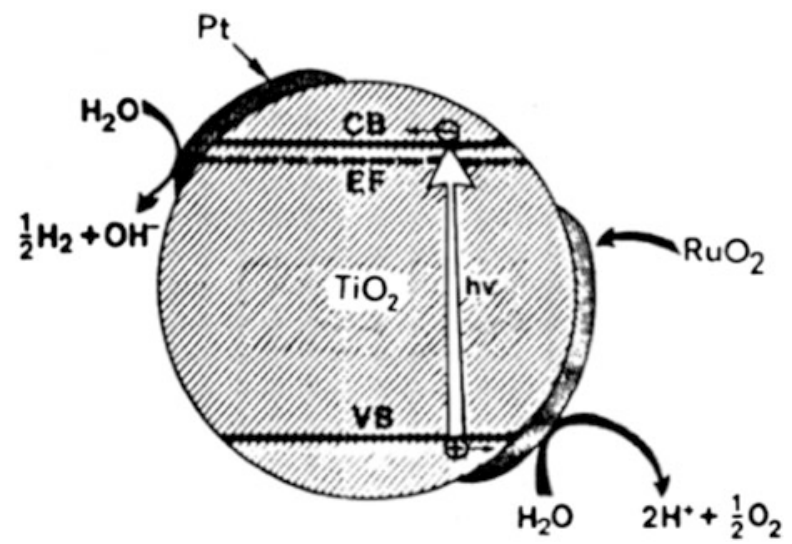

Fig. 2 Photoelectrochemical diode after Duonghong et al. Reproduced with permission from [42]. Copyright 1981, American Chemical Society

water electrolysis, PCs are nearly one order of magnitude cheaper than photoelectrochemical cells at equal efficiency $[25,26]$. At $10 \%$ energy efficiency, PCs could deliver hydrogen at a cost of $\$ 1.63$ per $\mathrm{kg}$, and outcompete oil as an energy carrier.

Photocatalysts operate as either type 1 (Schottky) or type 2 (tandem) devices (Fig. 1) [9, 27-31]. In type $1 \mathrm{PCs}$, light absorption and charge separation occur at a single absorber particle connected to one or several co-catalysts to complete the circuit for water electrolysis. The ideal limiting Solar-to-Hydrogen (STH) efficiency of this Schottky-type configuration is $\eta=14.4 \%$, based on a light absorber with a $2.0 \mathrm{eV}$ band gap and conversion losses of $E_{\text {Loss }}=0.8 \mathrm{eV}$ per electron [11, 12]. Actual type 1 photocatalysts such as $\mathrm{NiO}$-modified $\mathrm{La}: \mathrm{KTaO}_{3}$ [32] and $\mathrm{Cr} / \mathrm{Rh}$ - 
modified $\mathrm{GaN}: \mathrm{ZnO}(\mathrm{QE}=2.5 \%$, pure water, visible light $)$ [33-35] achieve less than $0.1 \%$ STH because of low sunlight absorption $\left(E_{\mathrm{G}}\right.$ of $\mathrm{La}: \mathrm{KTaO}_{3}$ is $\left.3.6 \mathrm{eV}\right)$ and recombination losses at the surfaces of the particles. A number of other catalysts, including $\mathrm{In}_{1-x} \mathrm{Ni}_{x} \mathrm{TaO}_{4}(x=0-0.2)$ [36, 37], $\mathrm{CoO}$ [38], and $\mathrm{Cu}_{2} \mathrm{O}$ [39], have also been reported. However, their performance has not yet been reproduced in the literature and remains in question $[40,41]$.

The type 2 photocatalyst is based on the tandem (or Z-scheme) concept shown in Fig. 1b. Here, two (or more) separate light absorbers are connected in series. Because the device voltage is divided into several contributions, semiconductors with smaller band gaps can be used which absorb a much greater fraction of the solar flux [43]. The ideal limiting STH efficiency of a dual absorber configuration is $24.4 \%$ (for a combination of absorbers with band gaps of 2.25 and $1.77 \mathrm{eV}$ ). This is nearly twice that of the Schottky junction catalysts $[11,12]$. However, because of the greater complexity (two absorbers instead of one), functional tandem PCs have only been known for about 15 years [16]. Of these, the combination of $\mathrm{Rh}: \mathrm{SrTiO}_{3}$ and $\mathrm{BiVO}_{4}$ connected with a $\mathrm{Fe}^{3+/ 2+}$ redox shuttle, gives the highest STH efficiency $(0.1 \%)$ [44].

Currently, there are three main strategies to develop more efficient, more stable, and less expensive PCs. One is to encapsulate traditional absorber materials from photovoltaics (e.g., IV, III/V, II-VI semiconductors) with protecting layers to inhibit photocorrosion. This strategy is has recently been applied to silicon, GaAs, and GaP photoanodes [45], and to cuprous oxide photocathodes [46], with reasonable success. Another approach involves the development of new metal oxide materials that combine suitable properties (visible band gap, high carrier mobilities, long carrier lifetimes) with greater chemical stability for photoelectrochemical water splitting. Such materials can be made by directed synthesis, sometimes guided by theory [47], or they can be made by combinatorial approaches, as described by Bruce Parkinson [48-50], Eric McFarland [51], and Nathan Lewis [52]. The third strategy is to exploit scaling laws and specific effects at the nanoscale [53-56] to overcome the limiting problems of metal oxide absorbers, such as their short electron-hole lifetimes and low mobility. This nanostructuring strategy has gained significant interest in the last 20 years [57-67] and is the focus of this chapter.

\section{Brief History of Nanoscale Water Splitting Photocatalysis}

The photosynthetic systems of bacteria are the earliest examples of nanostructured solar energy conversion devices; they date back to the beginning of life on this planet [68]. In contrast, artificial nanostructures for solar energy to fuel conversion have emerged only in the last three decades. The first experimental work dates back to 1968 , when Boddy established photoelectrochemical water oxidation with an 
illuminated $\mathrm{TiO}_{2}$ electrode [69], and Freund and Gomez reported similar reactions on $\mathrm{ZnO}, \mathrm{TiO}_{2}$, and $\mathrm{WO}_{3}[70]$. However, the potential of the reaction for artificial photosynthesis was only recognized broadly with Fujishima and Honda's report in Nature $[71,72]$. The idea to carry out this process with 'miniaturized photoelectrochemical cells' suspended in water gained traction after Arthur Nozik formulated the concept of 'photochemical diodes' [29]. This was quickly followed by experimental demonstrations of photocatalytic effects in suspended semiconductor particles by Bard [43], and on 'colloidal microelectrodes' by Henglein [54, 73]. In 1979, Michael Grätzel reported photocatalytic water oxidation by a suspended $\mathrm{RuO}_{2}$ nanoparticle in the presence of a $\left[\mathrm{Ru}(\text { bipy })_{3}\right]^{2+}$ complex for visible light absorption and methyl viologen $\left(\mathrm{MV}^{2+}\right)$ as sacrificial electron acceptor [74]. An improved system consisted of a $\mathrm{TiO}_{2}$ colloidal light absorber and $\mathrm{Pt}$ and $\mathrm{RuO}_{2}$ co-catalysts for water reduction and oxidation, respectively (Fig. 2) [42]. Even though water splitting was not achieved in this system $\left(\mathrm{O}_{2}\right.$ evolution was later attributed to air contamination) [28, 75], the structure exemplifies the design principles of a 'photochemical diode' [76]. Contemporary research on nanoscale water splitting catalysts is motivated by the prospect of extracting charge carriers more efficiently and thereby overcoming the limitations of metal oxide absorbers (short carrier lifetimes and low mobility). The underlying concepts are the topics for the next sections.

\section{Size Dependency of Free Energy Creation in Photocatalysts}

The effects of nanostructuring the light absorber on free energy conversion can be illustrated well with an equivalent circuit diagram for a photovoltaic cell. In the diagram in Fig. 3, the light-absorbing component corresponds to a photon-driven current source, and the rectifying (charge separating) component is shown as a diode connected in parallel to it. In addition, there are parallel and serial resistances, $R_{\mathrm{SH}}$ and $R_{\mathrm{S}}$. The former is associated with the non-selective charge transfer which leads to leakage or shunting, whereas the latter is produced by the transport of charge carriers from the absorber interior to the interface. For a photovoltaic cell, the load is an electrical device, and for a fuel-producing photocatalyst the load is water electrolysis [77].

In the circuit, $I_{\mathrm{SH}}, R_{\mathrm{S}}$, and $R_{\mathrm{SH}}$ are dependent upon the physical size of the junction. For two otherwise identical junctions, the one with twice the surface area of the other is expected to have half the shunt resistance and double the leakage current $I_{\mathrm{SH}}$ because it has twice the junction area across which current can leak. It also has half the series resistance $R_{\mathrm{S}}$ because it has twice the cross-sectional area through which current can flow. For a nanostructured photocatalyst, the decrease in $R_{\mathrm{SH}}$ corresponds to the leakage currents $J_{\mathrm{et}}$ and $J_{\mathrm{T}}$ in Fig. 12. If the leakage current exceeds the generation current $I_{\mathrm{L}}$, water electrolysis comes to a stop. On the other 
Fig. 3 Equivalent circuit diagram for a photovoltaic cell. $R_{\mathrm{SH}}$ : shunt resistance, $R_{\mathrm{S}}$ : serial resistance, $I_{\mathrm{SH}}$ : leakage current, $I_{\mathrm{L}}$ : generation current

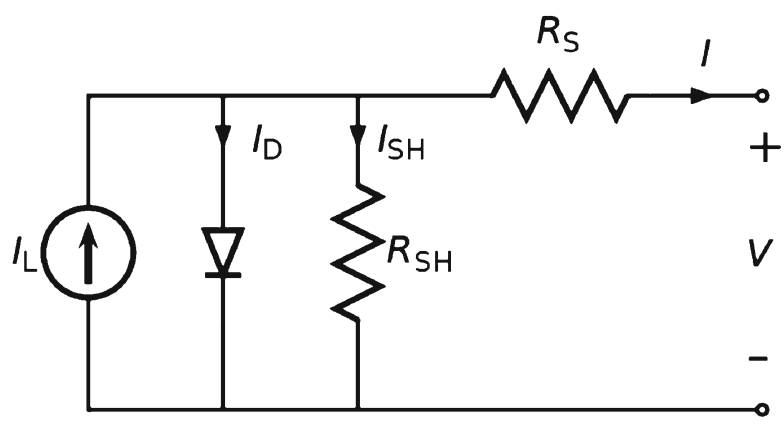

hand, the decrease of $\mathrm{R}_{\mathrm{S}}$ caused by the reduction in electron-hole transport resistances improves the photocurrent. Finally, as the semiconductor particles approach the nanoscale, reduced space charge layer effectiveness diminishes the rectifying properties. This corresponds to reduction of $R_{\mathrm{SH}}$.

\section{Light Absorption}

The ability of a material to absorb light is determined by the Lambert-Beer law and the wavelength-dependent absorption coefficient $\alpha$. The light penetration depth $\alpha^{-1}$ refers to the distance after which the light intensity is reduced to $1 / e$ of the incident illumination. For example, for $\mathrm{Fe}_{2} \mathrm{O}_{3}, \alpha^{-1}=118 \mathrm{~nm}$ at $\lambda=550 \mathrm{~nm}$ [7]; for CdTe, $\alpha^{-1}=106 \mathrm{~nm}(550 \mathrm{~nm})$ [78]; and for Si, $\alpha^{-1}=680 \mathrm{~nm}(510 \mathrm{~nm})$. To ensure $>90 \%$ absorption of the incident light, the film thickness $d$ must be $>2.3$ times the value of $\alpha^{-1}$ (Fig. 4). The dimensions of nanostructured photocatalysts are usually smaller than $\alpha^{-1}$, so each nanoparticle only absorbs a small fraction of the incident light. However, complete light absorption by the suspension can be achieved by adjusting the particle concentration and optical pathlength of the reaction container. Nanostructured surfaces also reduce the reflection losses and increase the light scattering. A solid film with one nanostructured surface (Fig. 4b) increases the horizontal light distribution. A particle suspension (Fig. 4c) increases the light distribution in three dimensions. This occurs by refraction at the surfaces of the particles and by Mie scattering. As a result, the light in a suspension impinges on the particles from all directions. This has an important consequence on the ability of the particles to generate a photovoltage at the solid-liquid interface and to generate the necessary thermodynamic driving force for water electrolysis. According to the Shockley diode equation (2) [77], the open circuit voltage $V_{\mathrm{OC}}$ of a solar cell is a logarithmic function of the absorbed flux $j_{\text {phot }}$ and of the reverse saturation current $j_{0}$ of the diode: 

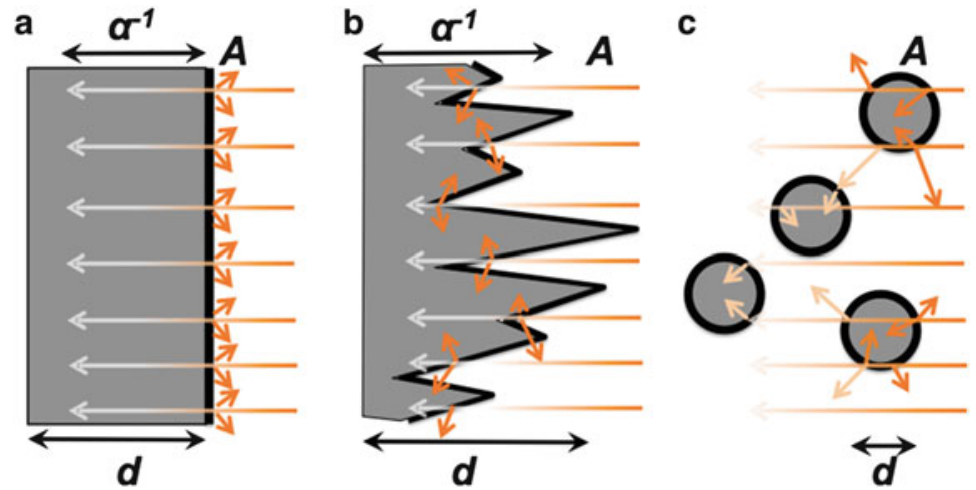

Fig. 4 Light distribution (a) in flat films, (b) in rough films, and (c) in particle suspensions. A: surface area; $d$ : film or particle thickness; $\alpha^{-1}$ : optical penetration depth. Short arrows show scattered or reflected light

$$
V_{\mathrm{OC}}=\frac{k T}{e} \ln \left(\frac{j_{\mathrm{phot}}}{j_{0}}+1\right) .
$$

By increasing the junction area A of the absorber (Fig. 4), the absorbed flux $j_{\text {phot }}$, defined as the photon rate per unit area of the junction, decreases proportionally and the photovoltage drops. For example, if $j_{\text {phot }}>>>j_{0}$, the photovoltage decreases by $0.059 \mathrm{~V}$ for every decadic decrease of $j_{\text {phot }}$ (i.e., decadic increase of junction area). This has been experimentally observed for silicon microwire arrays [79]. Equation (2) also impacts the construction of photocatalysts. It emphasizes the need to minimize the solid-liquid junction area through inert coatings or by replacing the solid-liquid junction with localized solid-solid junctions on the surface of the light absorber.

\section{Majority and Minority Carrier Transport}

Photoexcitation produces charge carriers with finite mobility and lifetime, depending on the material, the carrier type, and the light intensity. To drive water redox reactions, these carriers need to reach the material's interfaces at the electrolyte and at the co-catalysts. In the absence of an external field, charge carriers move by diffusion. Their range is defined by the mean free diffusion length $\mathrm{L}$ which depends on the carrier diffusion constant $\mathrm{D}$, the carrier lifetime $\tau$, and a dimensionality factor ( $q=2,4$, or 6 for one-, two-, or three-dimensional diffusion): 

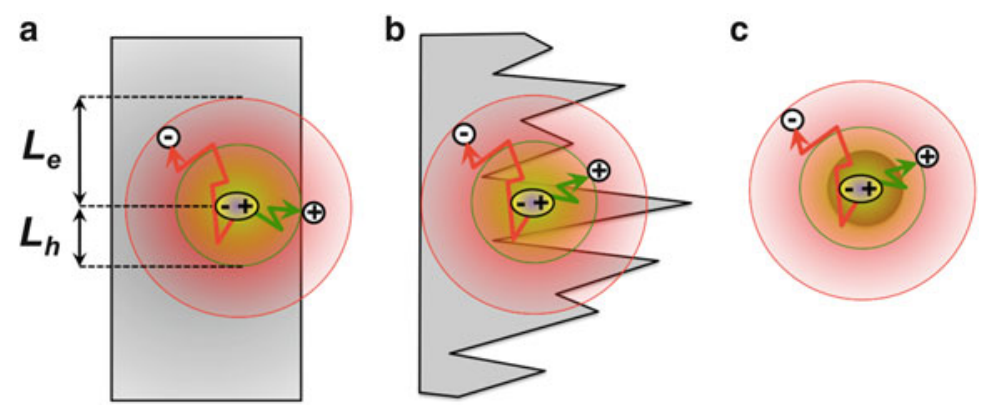

Fig. 5 Charge collection (a) in flat films, (b) in nanostructured films, and (c) in particle suspensions. $d$ : film or particle thickness; $L_{\mathrm{e}}$ : electron diffusion length; $L_{\mathrm{h}}$ : hole diffusion length

$$
\overline{L^{2}}=q D \tau
$$

For intrinsic semiconductors, usually $L_{\mathrm{e}}>L_{\mathrm{h}}$ because of the larger diffusion constant $D$ of electrons compared to holes. For example, Si has $D_{\mathrm{e}}=49 \mathrm{~cm}^{2} \mathrm{~s}^{-1}$ and $D_{\mathrm{h}}=13 \mathrm{~cm}^{2} \mathrm{~s}^{-1}$ (calculated from mobilities, $\mu_{\mathrm{e}}=1,900 \mathrm{~cm}^{2} \mathrm{~V}^{-1} \mathrm{~s}^{-1}$, and $\mu_{\mathrm{h}}=500 \mathrm{~cm}^{2} \mathrm{~V}^{-1} \mathrm{~s}^{-1}$ at $298 \mathrm{~K}$ using the Einstein-Smoluchowski relation) [80] assuming $\tau_{\mathrm{e}}=\tau_{\mathrm{h}}=10^{-6} \mathrm{~s}, L_{\mathrm{e}}=98 \mu \mathrm{m}$, and $L_{\mathrm{h}}=51 \mu \mathrm{m}$ for one-dimensional diffusion $(q=2)$. Upon doping, the concentration of the majority carriers increases, and with it their $\tau$ and $L$ values. On the other hand, the lifetime and diffusion length of the minority carriers decrease. For optimum collection of both carrier types at the interface, the semiconductor film thickness $d$ has to be in the same range as $L_{\mathrm{e}}$ and $L_{\mathrm{h}}$ (Fig. 5). This can be achieved by increasing the surface roughness of the film, as shown in Fig. 5b. Such a surface nanostructuring approach is particularly useful for first-row transition metal oxides $\left(\mathrm{Fe}_{2} \mathrm{O}_{3}\right)$, which suffer from low hole mobility and short hole lifetimes [81, 82]. Ideal electron-hole collection is possible with suspended nanoparticles if their particle size $d<L_{\mathrm{e}}, L_{\mathrm{h}}$.

The impact of the absorber size on charge collection has been experimentally verified with nanoparticles and bulk particles of $\mathrm{KCa}_{2} \mathrm{Nb}_{3} \mathrm{O}_{10}$ [83, 84]. Chemical exfoliation of this layered Dion-Jacobson phase affords 1-2 nm thick sheet-like tetrabutylammonium stabilized $\mathrm{HCa}_{2} \mathrm{Nb}_{3} \mathrm{O}_{10}$ nanoparticles, whereas sonication leads to $227 \pm 202$-nm particles referred to as 'bulk' (Fig. 6). Both types of particles photocatalyze hydrogen evolution from aqueous methanol under UV light illumination, but hydrogen evolution rates for the nanosheets are consistently higher than those for the bulk particles, even in the presence of co-catalysts. Rates can be fitted to the kinetic model as in Fig. 6c and as expressed in (4):

$$
\mathrm{ER}=\left(\frac{1}{R_{\mathrm{G}}-R_{\mathrm{R}}^{\mathrm{L}}-R_{\mathrm{R}}^{\mathrm{S}}}+\frac{r}{J_{\mathrm{CT}}^{-}}+\frac{r}{J_{\mathrm{CT}}^{+}}+\frac{d_{\mathrm{OX}}}{J_{\mathrm{OX}}}+\frac{d_{\mathrm{RED}}}{J_{\mathrm{RED}}}+\frac{1}{R_{\mathrm{OX}}}+\frac{1}{R_{\mathrm{RED}}}\right)^{-1} .
$$



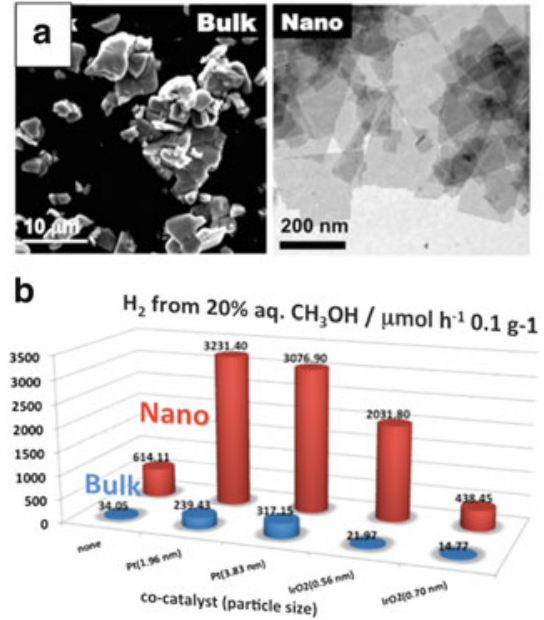

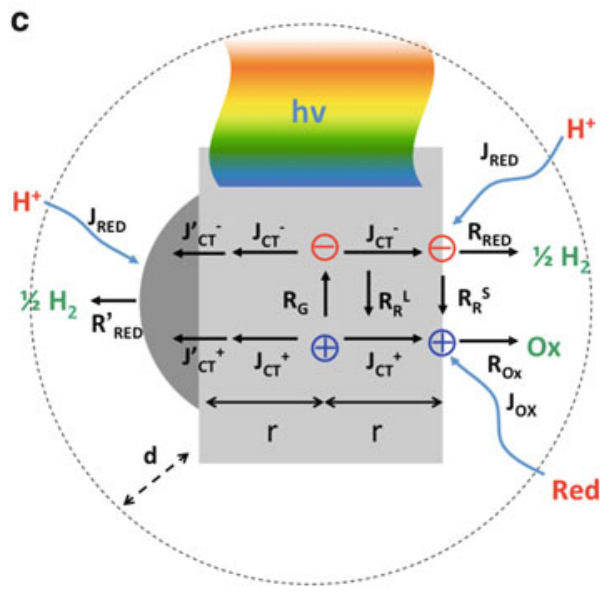

Fig. 6 (a) Electron micrographs of bulk and nanoscale niobate particles. (b) $\mathrm{H}_{2}$ evolution rates of bare and co-catalyst modified particles. (c) Model to relate the electronic rate of the catalyst $\left(\mathrm{mol} \mathrm{s}{ }^{-1} \mathrm{~cm}^{-3}\right)$ to the rates for light-induced electron-hole generation $\left(R_{\mathrm{G}}\right)$, electron-hole recombination in the lattice $\left(R_{\mathrm{R}}{ }^{\mathrm{L}}\right)$ and on the surface $\left(R_{\mathrm{R}}^{\mathrm{S}}\right)$, rates for charge and mass transfer to the catalyst-water interface $\left(J_{\mathrm{CT}}, J_{\mathrm{MT}}\right)$, and to the rates for the redox reactions with the substrates $\left(R_{\mathrm{RED}}, R_{\mathrm{OX}}\right)$. Reproduced with permission from [84]. Copyright 2012, American Chemical Society

The model calculates the electronic rate of the catalysts as a sum of the inverse rates of charge generation $R_{\mathrm{G}}$, charge and mass transport $J_{\mathrm{CT}}$, chemical conversion $J_{\mathrm{OX} / \mathrm{RED}}$, and charge recombination $R_{\mathrm{R}}$. This one-dimensional continuity analysis $[66,85-88]$ is equivalent to Kirchhoff's law, according to which the total resistance of a series of resistors equals the sum of the individual resistances. The analysis shows that the activity of the photocatalysts is limited by the slowest kinetics in the series. Under the experimental conditions (sacrificial donor), these are the rates of charge transport to the water-catalyst interface and of proton reduction. Mass transport in the solution phase does not play a significant role, and neither does surface recombination.

The effect of nanoscaling on the ability to extract short-lived minority carriers is also evident in colloidal $\mathrm{Fe}_{2} \mathrm{O}_{3}$ dispersions, which catalyze the oxygen evolution reaction with aqueous $0.1 \mathrm{M} \mathrm{AgNO}_{3}$ as the sacrificial electron acceptor [89]. Even though the performance of the system is limited by silver deposition on the $\mathrm{Fe}_{2} \mathrm{O}_{3}$ nanocrystals (Fig. 7), a correlation between $\mathrm{O}_{2}$ production rates and particle size is seen. This can be attributed to improved hole extraction in the smaller nanocrystals [89]. In principle, by reducing the nanocrystal size further, and by increasing the thermodynamic driving force for charge extraction, most metal oxide materials can be turned into photocatalysts. The photocatalytic properties of $2 \mathrm{~nm} \mathrm{IrO}_{2}$ nanocrystals illustrate this principle. Because $\mathrm{IrO}_{2}$ is metallic [90], the lifetime of the photogenerated holes is on the picosecond time scale. Nevertheless, visible and UV-light induced photocatalytic oxygen evolution from $\mathrm{IrO}_{2}$ sols can be observed 

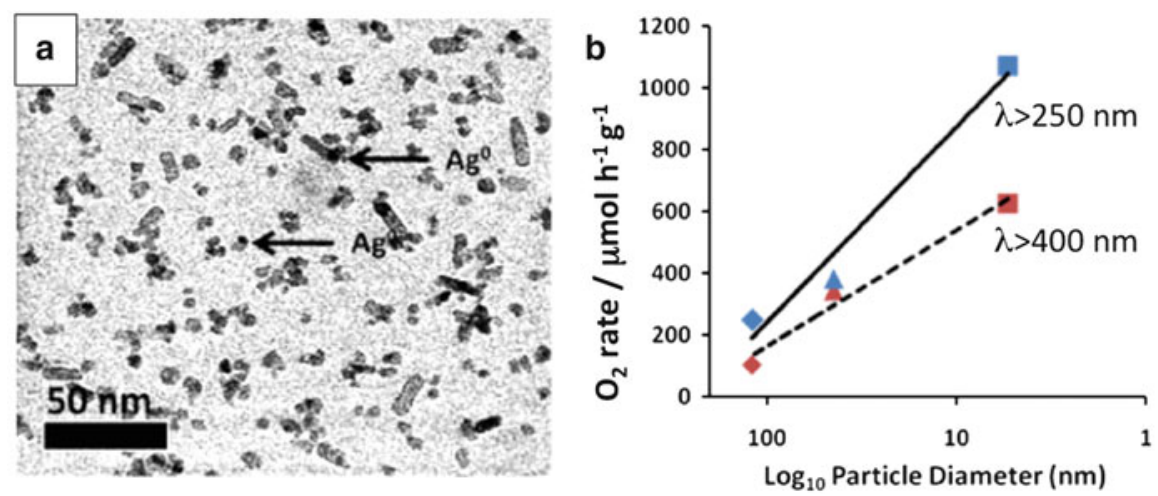

Fig. 7 (a) Silver nanoparticles formed on nano- $\mathrm{Fe}_{2} \mathrm{O}_{3}$ after irradiation in aqueous $\mathrm{AgNO}_{3}$. (b) Correlation between $\mathrm{Fe}_{2} \mathrm{O}_{3}$ particle size and $\mathrm{O}_{2}$ evolution rate. Reproduced with permission from [89]. Copyright 2011, Royal Society of Chemistry

in the presence of silver nitrate or sodium persulfate sacrificial electron acceptors [91]. However, the quantum efficiency for the process is too low $(0.19 \%$ at $530 \mathrm{~nm})$ to be useful for solar energy to fuel conversion. This principle also explains photocatalysis with Plasmonic gold nanoparticles.

\section{Quantum Size Confinement}

The observation of quantum size effects in thin films and quantum dots (QDs) dates back to the work by Dingle [53] and Louis Brus [56]. Quantum size effects not only depend on the material and crystal size, but also the nanocrystal shape [92]. The expanded band gap shifts the conduction and valence band edges to more reducing and more oxidizing potentials, respectively. From Marcus-Gerischer theory it is expected that this increase in thermodynamic driving force raises the rates of interfacial charge transfer and water electrolysis [88, 93, 94]. Increases in solidsolid electron transfer were experimentally confirmed for $\mathrm{CdQ}(\mathrm{Q}=\mathrm{S}, \mathrm{Se})-\mathrm{TiO}_{2}$ composites [95, 96], and quantitatively described with Marcus theory [97]. In 2013, the author's group established a similar rate dependence for proton reduction with CdSe quantum dots (Fig. 8) [98, 99]. For the study, monodisperse CdSe QDs with diameter 1.8-6.0 nm were synthesized in the presence of 2-mercaptoethanol as a ligand [100], followed by size-selective precipitation with 2-propanol. As can be seen from Fig. 8a, the hydrogen evolution rates from the CdSe QD suspensions in $\mathrm{Na}_{2} \mathrm{SO}_{3}$ solution show a logarithmic dependence on the crystal diameter.

A logarithmic plot of the rates against the driving force of the reaction is also linear (Fig. 8b). The quasi Fermi energies $E_{\mathrm{Fn}}$ were obtained from either the photocurrent onset in photoelectrochemical measurements or extrapolated from the electrochemical reduction peak of the QDs. The trend is expected for free energy-controlled interfacial charge transfer, as described by the Butler-Volmer equation [101]. As 
a

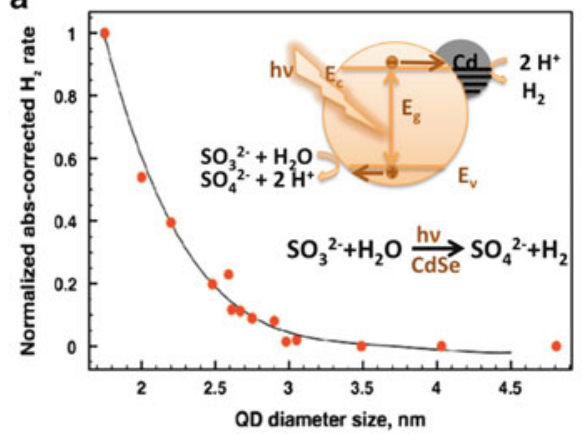

b

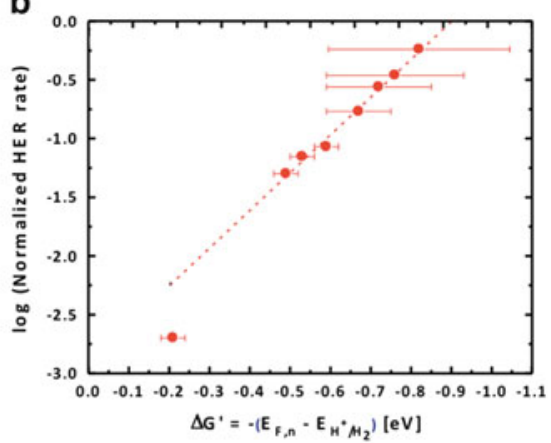

C

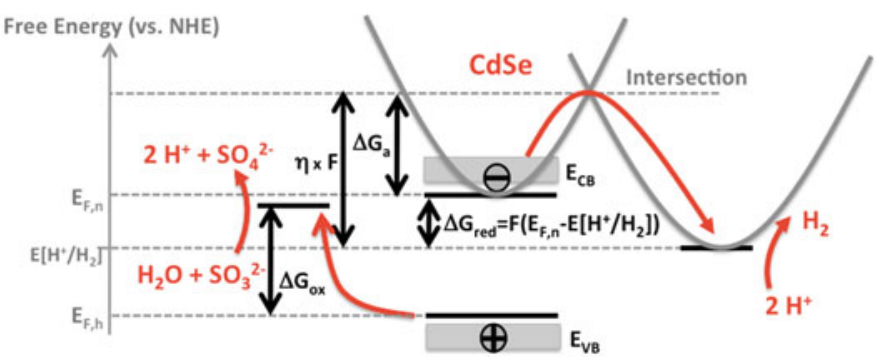

Fig. 8 (a) $\mathrm{H}_{2}$ evolution rates vs QD size. Rates are normalized with regard to catalyst amount and absorbed photons. Inset: Schematic diagram of hydrogen evolution from CdSe QDs in the presence of sodium sulfite. (b) Weighted least square linear fit (dashed line) of experimental $\mathrm{H}_{2}$ rates vs Fermi energies from electrochemistry. The lowest point is excluded from the fit because the rate is close to experimental error $\left( \pm 10^{-3}\right)$ of the $\mathrm{H}_{2}$ rate measurement. (c) Reaction energy profile for CdSe QD redox system. The kinetic activation energy $\Delta G_{\mathrm{a}}$ for proton reduction is controlled by the Gibbs free energy change $\Delta G_{\text {red }}$ of the reaction, as given by the quasi-Fermi level of electrons under illumination $E_{\mathrm{F}, \mathrm{n}}$ and the Nernst potential $E\left[\mathrm{H}^{+} / \mathrm{H}_{2}\right]$. Reproduced with permission from [99]. Copyright 2013, American Chemical Society

shown in Fig. 8c, there are two half reactions at the QD interface, the oxidation of sulfite and the reduction of protons. The driving force $\Delta G_{\mathrm{ox}}$ for the oxidation reaction is given by the difference between $E_{\mathrm{F}, \mathrm{h}}$ and $E\left[\mathrm{SO}_{4}{ }^{2-} / \mathrm{SO}_{3}{ }^{2-}\right]$ and the driving force for the reduction $\Delta G_{\text {red }}$ by the difference between $E_{\mathrm{F}, \mathrm{n}}$ and $E\left[\mathrm{H}^{+} / \mathrm{H}_{2}\right]$. Compared to $\Delta G_{\text {red }}, \Delta G_{\mathrm{ox}}$ for sulfite oxidation is large and relatively constant across the series of QDs. Thus, the proton reduction kinetics are the rate-limiting factor for the photocatalytic hydrogen evolution over CdSe QDs. Overall, these findings establish a quantitative experimental basis for quantum-confinement-controlled proton reduction with semiconductor nanocrystals.

In metal oxides, quantum confinement effects usually require crystal sizes below $2 \mathrm{~nm}$. That is because electron-hole pairs are less delocalized, and, correspondingly, their Bohr exciton radius is small [82]. Such conditions are fulfilled for $0.71 \mathrm{~nm}$ thick $\mathrm{WO}_{3}$ nanosheets obtained by exfoliation of the layered compound $\mathrm{Bi}_{2} \mathrm{~W}_{2} \mathrm{O}_{9}$ (Fig. 9) [102]. Diffuse reflectance optical spectra reveal an absorption edge of $430 \mathrm{~nm}$, consistent with a band gap of $2.88 \mathrm{eV}$, compared to $2.68 \mathrm{eV}$ for bulk 

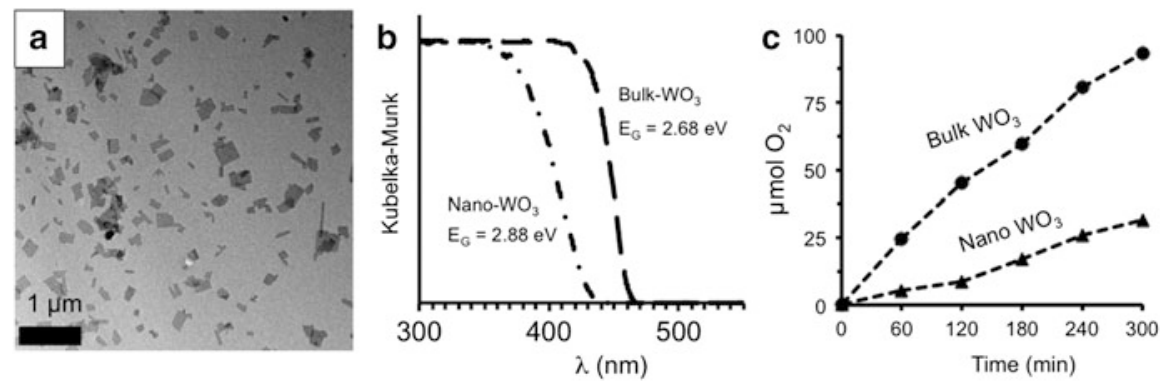

Fig. 9 (a) TEM image of nano- $\mathrm{WO}_{3}$. (b) Optical absorption of nano- $\mathrm{WO}_{3}$ and bulk particles. (c) $\mathrm{O}_{2}$ evolution from aqueous $0.0083 \mathrm{mM} \mathrm{AgNO}$ with $50 \mathrm{mg} \mathrm{WO}$ and under $>400 \mathrm{~nm}$ light from $300 \mathrm{~W}$ Xe lamp (315 $\mathrm{mW} \mathrm{cm}^{-2}$ ). Reproduced with permission from [102]. Copyright 2012, American Chemical Society

$\mathrm{WO}_{3}$. Under visible light illumination, the photocatalytic $\mathrm{O}_{2}$ evolution from such nanosheets is lower than the bulk because of reduced light absorption. However, the quantum efficiency for oxygen evolution at $375 \mathrm{~nm}(1.55 \%)$ exceeds that of the bulk $(1.43 \%)$. This is because of the greater free energy stored in the nanosheets.

\section{Multiple Exciton Generation}

The altered electronic structure of strongly size-confined nanocrystals gives rise to multiple exciton generation (MEG), i.e., the formation of several (n) electron hole/ pairs after absorption of one photon with an energy $\mathrm{n}$ times that of the particle's band gap (Fig. 10). The MEG effect has been made responsible for the abnormally high efficiency of $\mathrm{PbSe}$-sensitized $\mathrm{TiO}_{2}$ photoelectrochemical cells [103] and $\mathrm{PbSe}$ photovoltaic cells [104].

The MEG effect has not yet been demonstrated for water splitting photocatalysts. The problem is that, for MEG, the band gap of the absorber needs to be an integer fraction of the exciting light. For the upper range of solar photons with $3.0 \mathrm{eV}$, this would correspond to $E_{\mathrm{G}}=1.50$ or less. Such a low band gap is not sufficient for water electrolysis, considering additional voltage losses from charge transfer and recombination. However, the MEG effect could potentially work for tandem or multi-junction photocatalysts, which utilize several small band gap absorbers in series. 
Fig. 10 Enhanced photovoltaic efficiency in QD solar cells by impact ionization (inverse Auger effect). This is promoted in QDs because of the lower rates of carrier relaxation. Reproduced with permission from [105]. Copyright 2002, Elsevier Science Ltd

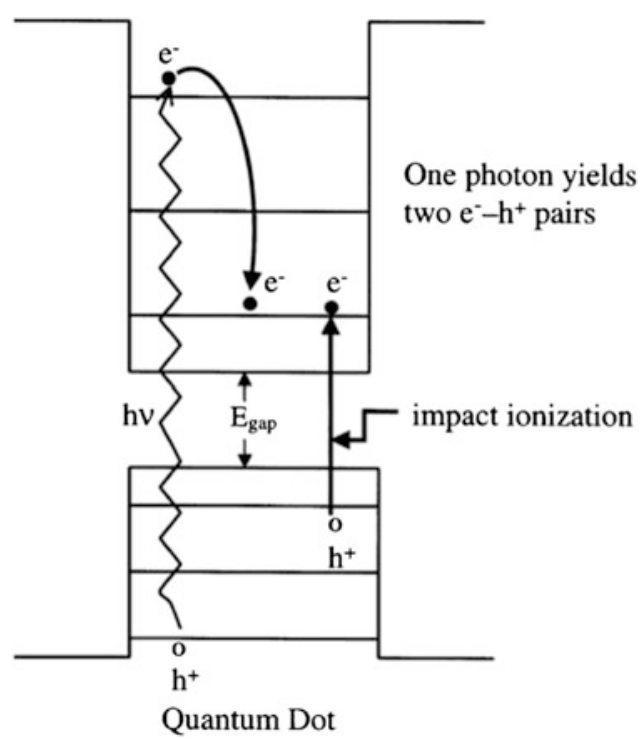

\section{Ion Effects}

Because the dimensions of nanomaterials are only a fraction of the space charge layer thickness in solid materials, screening effects from electrolytes and specifically adsorbed ions are dominant. For pure water, the most important ions are hydroxide and hydronium ions, and their effect on metal oxides, including $\mathrm{TiO}_{2}$ [106] and $\mathrm{Fe}_{2} \mathrm{O}_{3}[107,108]$ gives rise to the well-known $59 \mathrm{mV} \mathrm{pH}{ }^{-1}$ variation of the flatband potential with the solution $\mathrm{pH}$ [109]. In surface water, phosphate, silicate, and fluoride ions are often strongly adsorbing [110], which determines the redox stability of many minerals [109]. In contrast, the flatband potentials of II/VI, III/V , and group IV semiconductors are more susceptible to adsorption of soft ligands, including sulfur [111], $\mathrm{HS}^{-}[112,113], \mathrm{HTe}^{-}[114,115]$, and $\mathrm{Cl}^{-}$ [116]. These often bind to specific crystal surfaces [114, 115] and control the open circuit voltage of photoelectrochemical cells [116, 117] and the water redox rate of suspended photocatalysts.

The effect of specifically adsorbed ions follows directly from the definition of the Fermi energy of the electrons $E_{\mathrm{F}}$ in a particle, which is equal to the chemical potential $\mu$ minus the electrical potential $\phi$ of the material ( $F$ : Faraday constant) [118].

$$
E_{\mathrm{F}}=\mu-\phi F
$$

Adsorbed ions can modify either $\mu$ or $\phi$, or both. In the literature, proton adsorption is usually considered as an effect on the chemical potential $\mu$. This leads to the known Nernstian dependence of the semiconductor flatband potential on solution 

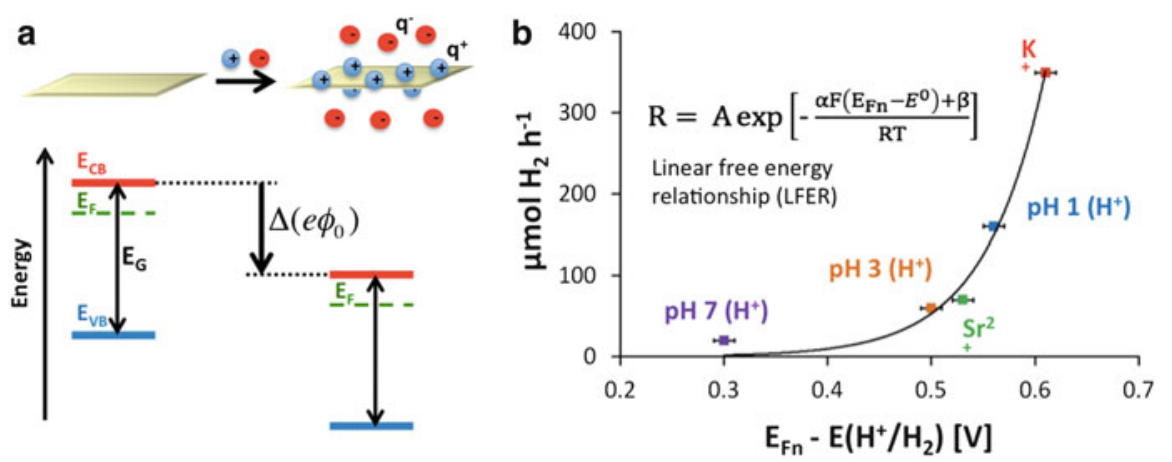

Fig. 11 (a) Effect of specifically adsorbed ions on the energetics of a sheet-like nanocrystal. (b) Calculated rate of hydrogen evolution vs $\Delta G$ for electron transfer with illuminated cation modified $\mathrm{KCa}_{2} \mathrm{Nb}_{3} \mathrm{O}_{10}$ nanosheets [123]. Constants: Faraday constant $F=96,485 \mathrm{C} \mathrm{mol}^{-1}$, ideal gas constant $R=8.314 \mathrm{~J} \mathrm{~mol}^{-1} \mathrm{~K}^{-1}, T=298 \mathrm{~K}$, free energy parameters $A=0.0127, \alpha=0.441$, and $\beta=633 \mathrm{~J} \mathrm{~mol}^{-1}$. Additional symbols in (6): relative permittivity $\varepsilon$ and dielectric constant $\varepsilon_{0}$. Reproduced from [123] with permission from The Royal Society of Chemistry

$\mathrm{pH}[106,107,109]$. Equation (5) works because redox reactions with protons are fast, allowing the protons to be in electrochemical equilibrium with the electrons in the particle. For ions such as $\mathrm{Al}^{3+}\left(-1.66 \mathrm{~V}\right.$ vs NHE) and $\mathrm{Mg}^{2+}(-2.37 \mathrm{~V}$ vs NHE) [119], whose negative reduction potentials preclude reduction in water, an electrostatic approach is more suitable (Fig. 11). Here it can be assumed that ion adsorption to the surface A generates the charge density $\sigma=q / A$, which modifies the surface potential $\phi_{0}$. Neglecting space charge layer effects, the potential $\phi$ felt inside the particle is the same as $\phi_{0}$, causing $E_{\mathrm{F}}$ to change according to (5). The relation between the surface charge density $\sigma$ and the surface potential $\phi_{0}$ is given by the Grahame equation (for definition of symbols see Fig. 11 caption) [120, 121]:

$$
\phi_{0}=\frac{2 R T}{z F} \sin ^{h-1}\left(\frac{\sigma}{\sqrt{8 R T \varepsilon \varepsilon_{0} c^{0}}}\right) .
$$

In it, $z$ and $c^{0}$ describe the charge and molar concentration of the counterions in solution, which surround the particle. Specifically, adsorbed cations produce a positive surface potential, shifting the energy bands down to more oxidizing potentials, and anions move the band edges to more reducing potentials. This shifts the Fermi energy in (5) and with it the driving force for photochemical charge transfer. In general, the variation of the electron transfer rate constant with $E_{\mathrm{F}}$ can be understood using free energy relationships [122], including Butler-Volmer [99, 101] and Marcus theory [94].

These theoretical predictions were recently verified for M-modified $\mathrm{KCa}_{2} \mathrm{Nb}_{3} \mathrm{O}_{10}$ nanosheets $\left(\mathrm{M}=\mathrm{H}^{+}, \mathrm{K}^{+}, \mathrm{Sr}^{2+}\right)$ [123]. Hydrogen evolution rates from the illuminated nanosheets are plotted in Fig. 11b against the thermodynamic 
driving force for proton reduction $F\left(E_{\mathrm{Fn}}-E^{0}\right)$, obtained from photoelectrochemistry. The data can be fitted with the linear free energy relationship (LFER) [122] shown in the figure (constants in caption). The numerical values of $\alpha$ and $\beta$ do not have physical significance, because the fitted rate $R\left(\mu \mathrm{mol} \mathrm{h}{ }^{-1}\right)$ does not convey any information about the value of the rate constant for the process, which depends on the electro-active area of the nanoparticles, the absorbed photons flux, space charge layer effects, and other unknown parameters [30, 124-128].The model provides a physical explanation for the observed correlation between nanosheet energetics and hydrogen evolution rates, and it confirms the dependence of photocatalytic activity on the presence of specifically adsorbed ions.

\section{Interfacial Charge Transfer}

The larger specific surface area of nanomaterials promotes charge transfer across the material interfaces (solid-solid and solid-liquid), allowing water redox reactions to occur at lower current densities and, correspondingly, lower overpotentials. This is a direct consequence of the Butler-Volmer equation which relates the current density to the overpotential [101]. This boost is particularly important for the slow, multi-step water oxidation reaction [129, 130], which normally requires highly active and often expensive co-catalysts based on Ir, Rh, or Pt [131]. It is one of the reasons why nanostructured electrocatalysts are so effective $[132,133]$. The problem for photocatalysts is that the increase in junction area also increases the rate for reverse charge transfer, as shown by $J_{\mathrm{T}}$ and $J_{\text {et }}$ in Fig. 12. These currents oppose the electron drift away from the surface (thick arrow) and reduce the rectifying character of the junction. The effect on the open circuit voltage of the junction is described with the Shockley diode equation (2). Every decadic increase of the reverse saturation current $J_{0}$ can be expected to decrease the open circuit voltage by $59 \mathrm{mV}$. The only way to overcome this fundamental limitation is by making the junction area smaller, as discussed above under Sect. 4.

\section{Electron-Hole Recombination}

Electron-hole recombination is the major loss mechanism in excitonic solar cells and in photocatalysts [135]. Photogenerated charge carriers recombine through radiative and nonradiative processes in the bulk phase of the semiconductor, in the depletion region, and at surface defects (Fig. 12) [134, 136-138]. These processes diminish the steady state concentrations of usable charge carriers, their charge transfer rates (thick black arrows in Fig. 12), and the driving force for water electrolysis. Furthermore, the larger specific surface area of the particles promotes non-radiative and interfacial recombination rates. The effect of these parameters on photocatalytic activity and electron-hole lifetime are commonly 


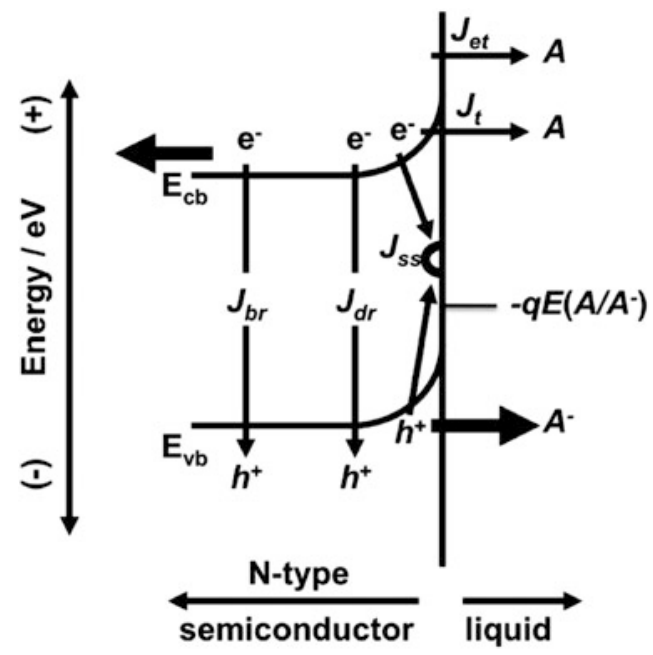

Fig. 12 Recombination pathways for photoexcited carriers in a semiconductor PEC [9, 134]. The arrows signify bulk recombination $\left(J_{\mathrm{br}}\right)$, depletion-region recombination $\left(J_{\mathrm{dr}}\right)$, and surface recombination $\left(J_{\mathrm{ss}}\right)$. Additional loss mechanisms caused by undesired charge transfer are also shown. Electron tunneling through and over the barrier produces the current densities $\left(J_{\mathrm{t}}\right)$ and $\left(J_{\mathrm{et}}\right)$. Electron collection by the back contact and hole collection by the redox couple (e.g., oxidation of water to $\mathrm{O}_{2}$ ) are desired processes shown by thick black arrows. Reproduced with permission from [134]. Copyright 2005, American Chemical Society

acknowledged in the literature [89, 139-143], but quantitative studies on this topic are rare [65, 79, 144-148].

We recently employed graphitic carbon nitride $\mathrm{g}-\mathrm{C}_{3} \mathrm{~N}_{4}$ to observe the effect of structure defects on the ability of the material to reduce protons photocatalytically and to generate a photovoltage [149]. Specifically, we observe an inverse relation between the photocatalytic hydrogen production rate from aqueous methanol and the calcination temperature (Fig. 13). Higher temperatures also decrease the photoluminescence (PL) of the material and the photovoltage. Based on the PL and surface photovoltage (SPV) data, there are two types of defects present near the conduction and valence band edges of the material. These defects promote electron-hole recombination and reduce the ability of the material to generate a photovoltage.

The reduction of surface defects must be a major goal for the future if nanostructured photocatalysts are to be used for unbiased solar water splitting [150]. The literature suggests that performance enhancements can be achieved with chemical treatments. For example, reaction of silicon with HF can suppress surface recombination and improve the performance of photovoltaic devices [138]. For $\mathrm{Fe}_{2} \mathrm{O}_{3}$ photoanodes it has been shown that application of $\mathrm{Al}_{2} \mathrm{O}_{3}$ [151] or $\mathrm{SnO}_{2}$ [152] overlayers also improves the performance. For $\mathrm{BiVO}_{4}$ photoanodes, both application of an $\mathrm{SnO}_{2}$ underlayer [153], and incorporation of $\mathrm{W}$ dopants boost the electrical power output, which is attributed to reduction of surface recombination 
a
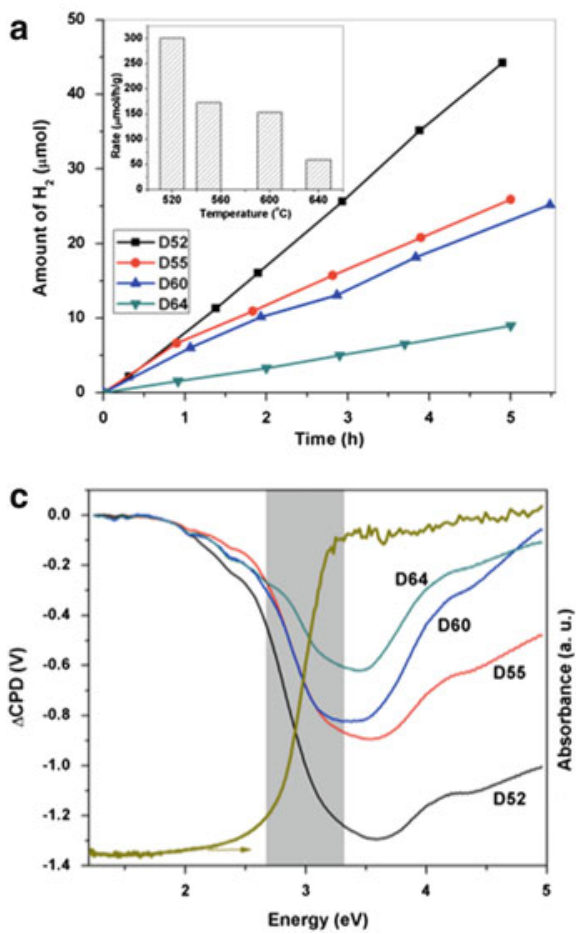

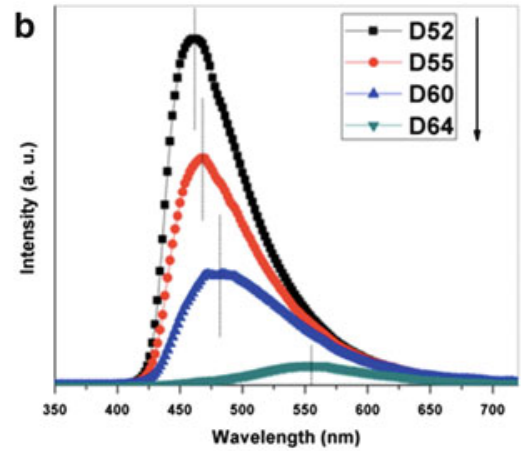

d

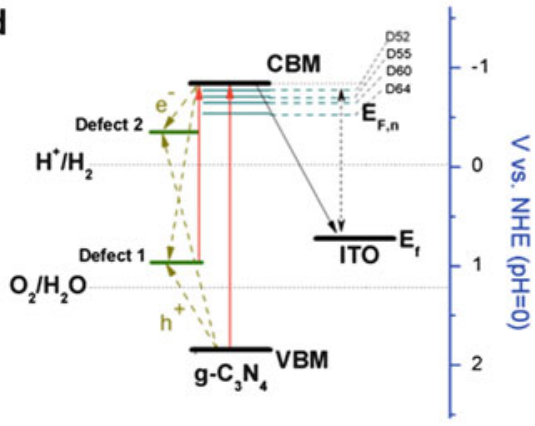

Fig. 13 Properties of $\mathrm{g}_{-} \mathrm{C}_{3} \mathrm{~N}_{4}$ prepared at 520, 550, 600, and $640^{\circ} \mathrm{C}$. (a) $\mathrm{H}_{2}$ evolution from platinated samples $(30 \mathrm{mg})$ in methanol $(20 \mathrm{vol} . \%)$ aqueous solution at $\mathrm{pH} 4.5$ under visible light $\left(>400 \mathrm{~nm}\right.$ ). (b) PL spectra at $350 \mathrm{~nm}$ excitation. (c) SPV spectra of $\mathrm{g}-\mathrm{C}_{3} \mathrm{~N}_{4}$ films on ITO substrate with UV-vis spectrum (dark yellow line) of D52. (d) Energy diagram of $\mathrm{g}_{-} \mathrm{C}_{3} \mathrm{~N}_{4}$ with defect levels at $+0.97 \mathrm{~V}$ and $-0.38 \mathrm{~V}$. Reproduced from [149] with permission from The Royal Society of Chemistry

[154]. Further work is needed to determine the general merit of these and related surface passivation approaches for suspended photocatalysts.

\section{Excited State Entropy}

Theoretically, the degree of quantum confinement of a light absorber determines the excited state entropy and its free energy [155]. According to (7) [156], the free energy of a semiconductor absorber $\mu_{\mathrm{e}, \mathrm{h}}$ is determined by the band gap $E_{\mathrm{G}}$, the temperature, the electron and hole concentrations $n_{\mathrm{e}}$ and $n_{\mathrm{h}}$, and the effective density of states $N_{\mathrm{CB} / \mathrm{VB}}$ near the band edges. The greater the $N_{\mathrm{CB} / \mathrm{VB}}$, the more diluted the charge carriers and the higher their entropy loss. In quantum dots, a reduction of $N_{\mathrm{CB} / \mathrm{VB}}$ can readily be achieved through quantum size effects (Fig. 14). Here, for $N_{\mathrm{CB}}=18,12,6$, and $n=6$ electrons, the number of microstates 

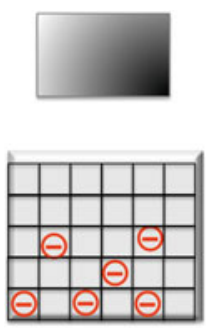

$$
\sigma_{\text {Bulk }}
$$

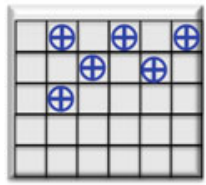

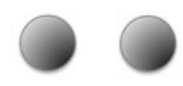
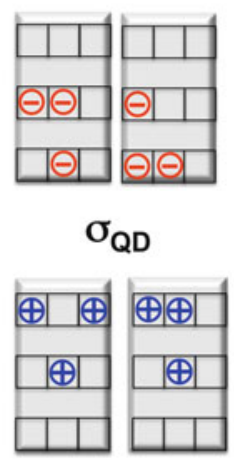
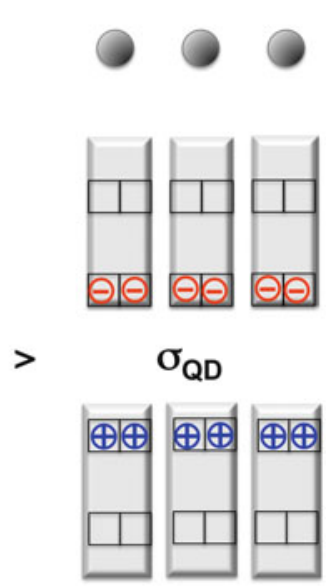

Fig. 14 Effect of quantum sizing on $N_{\mathrm{CV} / \mathrm{VB}}$ and entropy for three systems of six electron-hole pairs. Reproduced from [155] with permission from The American Chemical Society

$W_{\text {Tot }}=18 ! /[(18-6) ! 6 !], 12 ! /[(12-6) ! 6 !], 6 ! /[(6-6) ! 6 !]$, and the entropy per electron $\sigma=1.5 \times 10^{-23}, 1.1 \times 10^{-23}, 0.0 \mathrm{~J} / \mathrm{K}$. Thus, the free energy increases with quantum confinement because of the reduction of the effective density of states near the band edges. Physically, this represents a concentration of charge carriers near the band edges. This is in addition to the increase of the potential energy of the charge carriers which results from the widening of the band gap.

$$
\mu_{\mathrm{e}, \mathrm{h}}=E_{\mathrm{G}}-k T \ln \frac{N_{\mathrm{CB}} N_{\mathrm{VB}}}{n_{\mathrm{e}} n_{\mathrm{h}}} .
$$

The entropy effect is difficult to observe in actual photocatalysts because of the presence of other loss mechanisms (e.g., non-radiative recombination). Furthermore, the energetics of nanoscale systems is very sensitive to variations in size, shape, and molecular environment. The corresponding increase in the ground state entropy of polydisperse and randomly packed quantum dots can reverse the entropy reduction of the individual subsystems. Additional entropy losses in particulate absorbers can occur as a result of the redistribution of light. Potentially, these losses can decrease the photovoltage by as much as $315 \mathrm{mV}$ [157].

\section{Electron-Hole Separation}

In nanomaterials, carrier separation (arrows in Fig. 12) is more difficult to achieve than in the bulk because at average doping concentrations $\left(n_{0}=10^{17} \mathrm{~cm}^{-3}\right)$ space charge layers are not effective on the nanoscale [30, 59, 158, 159]. Also, for 
Fig. 15 Space charge layers in large and small particles. Reproduced with permission from [30]. Copyright 1994, Springer Berlin/Heidelberg
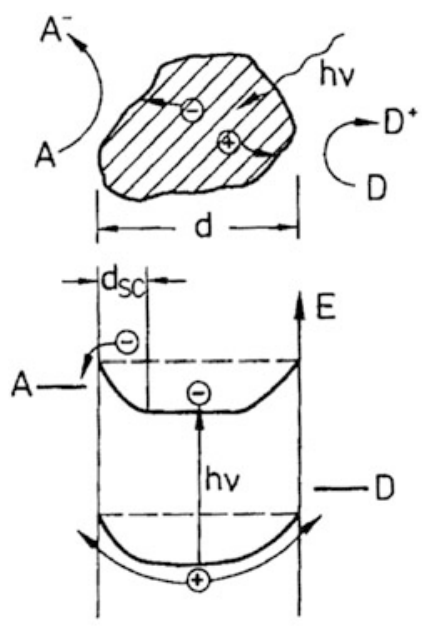

$d>d_{S C}$
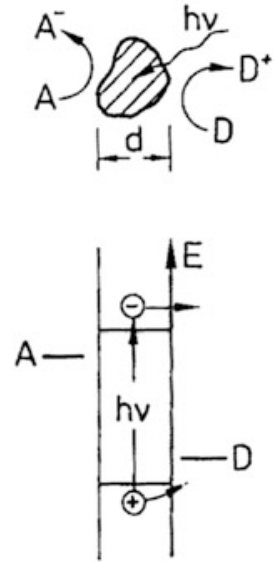

$\mathrm{d} \ll \mathrm{d}_{\mathrm{SC}}$

spherical nanoparticles, the space charge layer thickness $d_{\mathrm{sc}}$ cannot exceed the radius $d / 2$ of the particle (Fig. 15), which restrains the possible barrier height at the interface. For example, for $16-\mathrm{nm} \mathrm{TiO}_{2}$ nanocrystals $(\varepsilon=160)$ with a charge carrier concentration of $n_{0}=10^{17} \mathrm{~cm}^{-3}$, O'Regan calculated a barrier height of $0.3 \mathrm{meV}$ under maximum depletion [160]. This means that, in the absence of a strong applied bias, the bands in a nanoparticle are essentially flat, as shown in Fig. 15.

In the absence of an interior electrical field, the relative rates of electron-hole injection into the electrolyte are governed by the kinetics of interfacial charge transfer alone [158]. This leads to an increase of undesirable processes (current densities $\left(J_{\mathrm{t}}\right)$ and $\left(J_{\text {et }}\right)$ in Fig. 12) which short-circuit the device. The absence of an internal mechanism for charge separation also increases electron-hole recombination, as discussed above. This is the reason why efficient collection of majority carriers in dye-sensitized cells with nanocrystalline $\mathrm{TiO}_{2}$ substrates depends on the presence of iodide as an easily oxidizable electron donor [160, 161]. Without iodide, only $4 \%$ of electrons can be harvested at the back contact because of recombination with holes on the Ru dye (this corresponds to $J_{\text {et }}$ and $J_{\mathrm{t}}$ in Fig. 12). Furthermore, in nanostructures with quantum size effects (e.g., in many metal chalcogenides), the electron-hole pairs are confined to a space smaller than the Bohr exciton radius. This means that additional energy is necessary to separate the charges. This is analogous to organic photovoltaic cells, where a higher exciton binding energy results from the lower dielectric constant of organic polymers [162].

Photochemical labeling can provide information about charge separation in suspended light absorbers [32, 163, 164]. Typically, a photocatalyst is irradiated in the presence of metal salt that forms insoluble deposits (e.g., $\mathrm{Pt}, \mathrm{Au}, \mathrm{MnO}_{x}, \mathrm{IrO}_{x}$ ) after accepting photogenerated electrons or holes. This helps to pinpoint the locations of the photocharges on the absorber surface. For nanosheets derived 

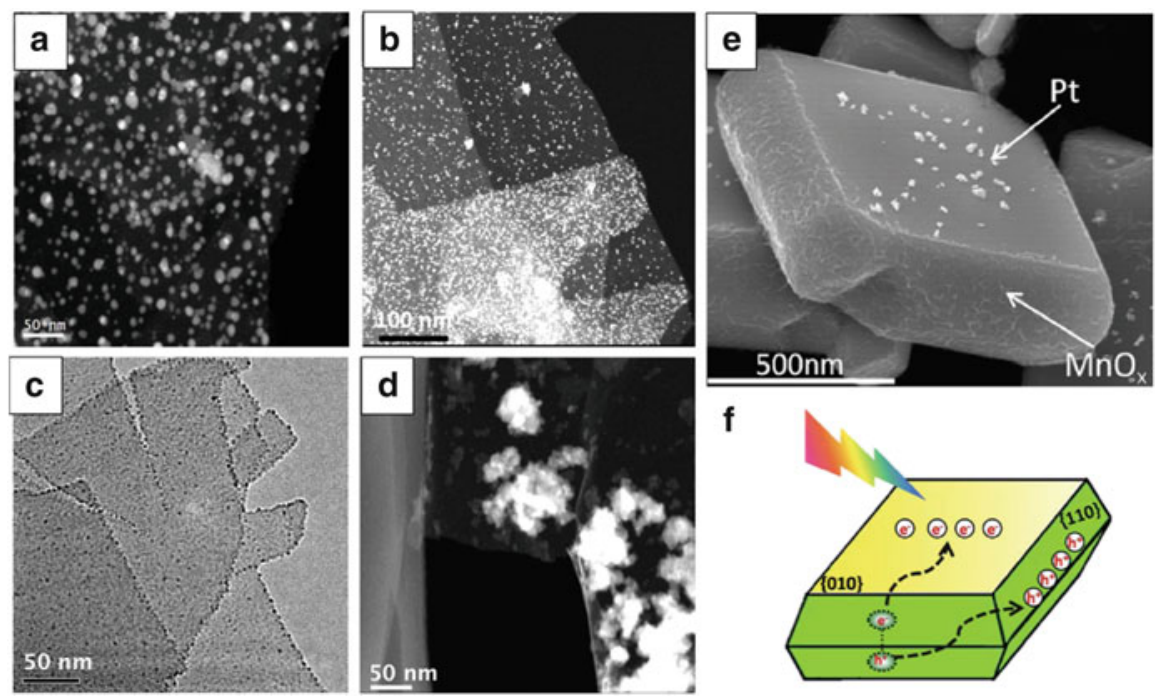

Fig. $16 \mathrm{HCa}_{2} \mathrm{Nb}_{3} \mathrm{O}_{10}$ nanosheets after labeling with (a) $\mathrm{Ag}$, (b) $\mathrm{Pt}$, (c) $\mathrm{IrOx}$, and (d) $\mathrm{MnOx}$ [165]. (e) $\mathrm{BiVO}_{4}$ microcrystals after labeling with Pt and $\mathrm{MnOx}$ (f) [166]. Reproduced from [166] with permission from The Royal Society of Chemistry

from the layered perovskite $\mathrm{KCa}_{2} \mathrm{Nb}_{3} \mathrm{O}_{10}$, non-selective labeling results support the lack of intra-sheet charge separation (Fig. 16) [165]. Better charge separation is generally found in microscale particles, especially those where facets with different surface potentials are present. This is shown for $\mathrm{BiVO}_{4}$ microcrystals in Fig. 16e, f. The selective deposition of $\mathrm{Pt}$ and $\mathrm{MnOx}$ suggests that charge carriers accumulate at (010) and (111) facets of the crystal [166].

In ferroelectric materials, local dipoles (Fig. 17) can aid photochemical charge separation $[167,168]$. Materials such as $\mathrm{BaTiO}_{3}$ support a spontaneous electrical polarization that stems from the displacement of mobile cations in the unit cell. Photochemical labeling experiments confirm that these dipoles can guide the accumulation of photochemical charge carriers [169]. The ferroelectric polarization appears to promote photocatalytic reactions [169], but its use for photocatalytic water splitting has not been tested.

Gradient doping provides an alternative way to generate a potential energy gradient inside of small crystals. This approach was recently demonstrated by van de Krol's group for tungsten-doped $\mathrm{BiVO}_{4}$ films. [170] A tungsten concentration gradient inside the films moves photoelectrons towards the electrode and holes towards the solid-liquid interface. This is an elegant way to control charge separation, but it is probably only usable in defect-tolerant semiconductors, such as $\mathrm{BiVO}_{4}$.

For the majority of other metal oxide particles, the use of electron or hole selective acceptors may be a more suitable approach to promote charge separation. Many transparent n- or p-type metal oxides are known to accept electrons or holes 

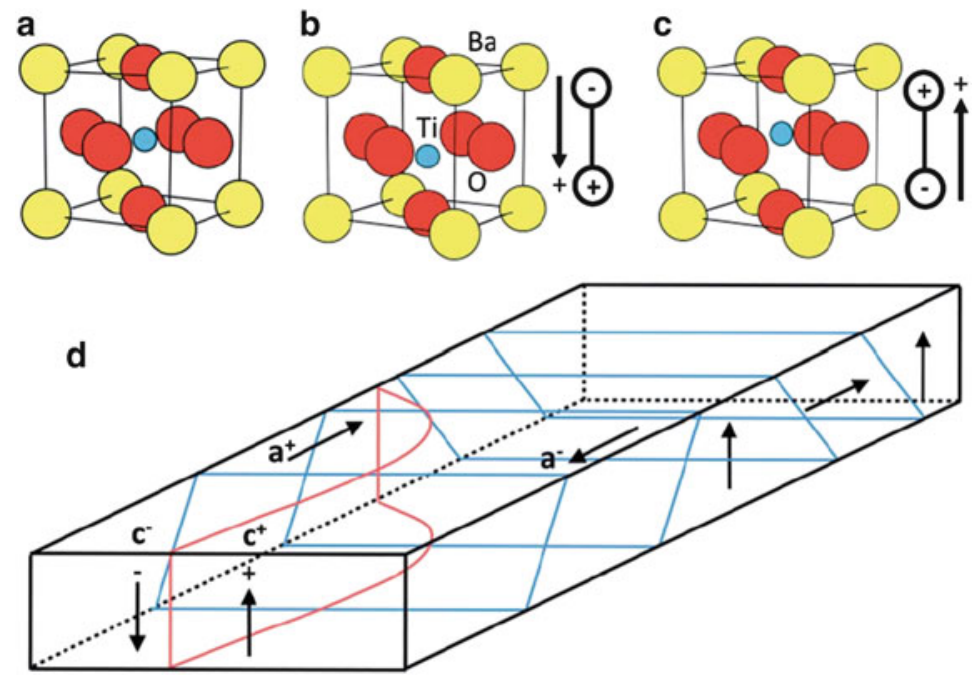

Fig. 17 Cubic unit cell of $\mathrm{BaTiO}_{3}$ above (a) and below (b, c) the Curie temperature. Note displacement of the central Ti(IV) ion and corresponding dipoles. (d) Crystal with domains of constant polarization in the arrow direction. Reproduced from [169]

selectively [171]. For example, $\mathrm{n}-\mathrm{SnO}_{2}$ underlayers on $\mathrm{BiVO}_{4}$ photoanodes have been found to boost the photocurrent by 300\% [153] and p-type $\mathrm{NiO}$ layers on $\mathrm{Fe}_{2} \mathrm{O}_{3}$ improved the photovoltage by nearly $0.4 \mathrm{~V}$ [172]. Many of these metal oxides can be deposited from solution and could potentially be applied to photocatalysts [173].

\section{Interparticle Charge Transport}

In nanocrystalline films, charge carriers move by diffusion instead of drift $[59,174$ 176]. As a result, charge transport is much slower than it is in the bulk phase, increasing the chances for recombination and back reactions [177]. If the nanoparticles are not fused together, additional barriers arise from interparticle charge transport, which occurs by thermally activated hopping and by electron tunneling (Fig. 18). Charge transport depends on the interparticle distance and the electrostatic charging energy of the donor acceptor nanocrystal couple [178, 179].

The problem of charge transport over macroscopic distance is less important with suspended catalysts. However, it does play a role for charge transport in photocatalyst films, as used for photoelectrochemical measurements, or with immobilized photocatalysts. 
Fig. 18 Electron hopping in nanostructured films. Reproduced from [178] by permission of the publisher (Taylor \& Francis Ltd., http://www.tandf.co.uk/ journals)

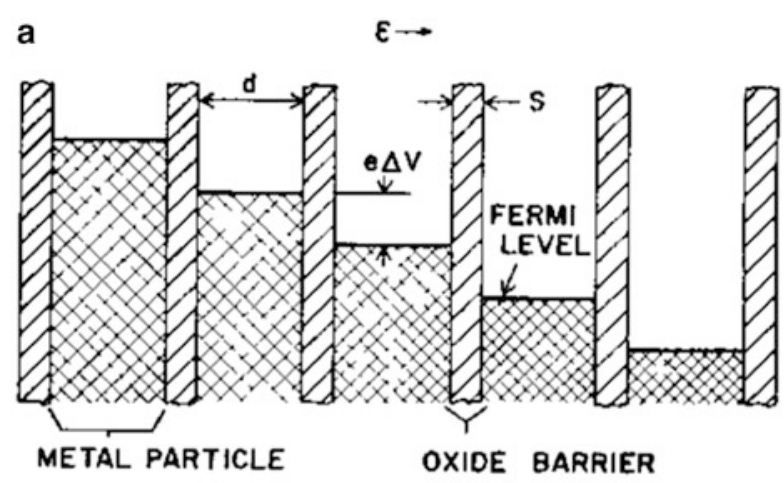

INITIAL STATE

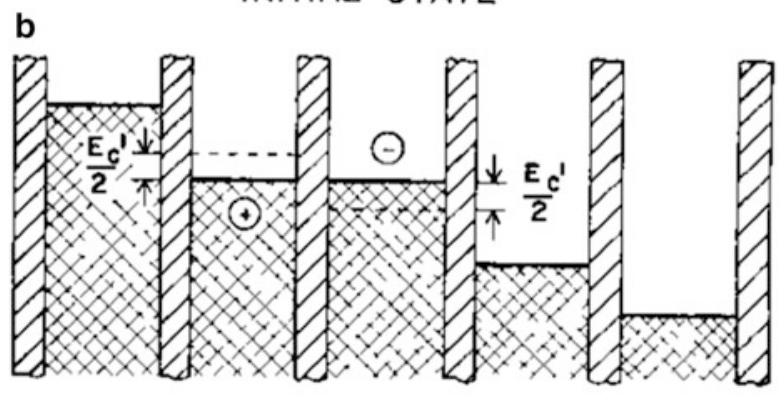

FINAL STATE

\section{Examples of Nanoscale Photocatalysts for Overall Water Splitting}

Because of the problems above, the number of known nanoscale photocatalysts for overall water splitting is limited [57-66]. Only five nanoscale photocatalysts have been reported in the literature. Four of them are Schottky type devices and require ultraviolet light for operation. The most active catalyst was reported by Kondo's group in 2011. It consists of aggregates of $\mathrm{NiO}_{x}$-loaded $\mathrm{NaTaO}_{3}$ nanocrystals (Fig. 19) [180]. The catalytic rate of this system was very high $\left(2.0 \mathrm{mmol} \mathrm{h}^{-1}\right.$ of $\mathrm{H}_{2}$ with stoichiometric $\mathrm{O}_{2}$ ) but required photons with $>4.0 \mathrm{eV}$ because of the band gap of bulk $\mathrm{NaTaO}_{3}$ [32]. The activity of the $20 \mathrm{~nm}$ nanoparticles was three times higher than that of the 50,100, and $200 \mathrm{~nm}$ particles tested for comparison. This was attributed to the higher surface area of the smallest absorber size and higher crystallinity.

Another system was developed by Akihiko Kudo's group and consists of $\mathrm{LiNbO}_{3}$ nanowires $(70 \mathrm{~nm} \times 10 \mu \mathrm{m})$ with a band gap of $4.0 \mathrm{eV}$ (Fig. 20) [142]. After modification with 1 mass $\% \mathrm{RuO}_{2}$ co-catalyst, the nanocomposite can split water with $0.7 \%$ quantum efficiency at $254 \mathrm{~nm}\left(\mathrm{O}_{2}\right.$ was evolved in slight excess). The lower activity of the bulk compared to the nanowires was attributed to surface defects resulting from ball-milling. 

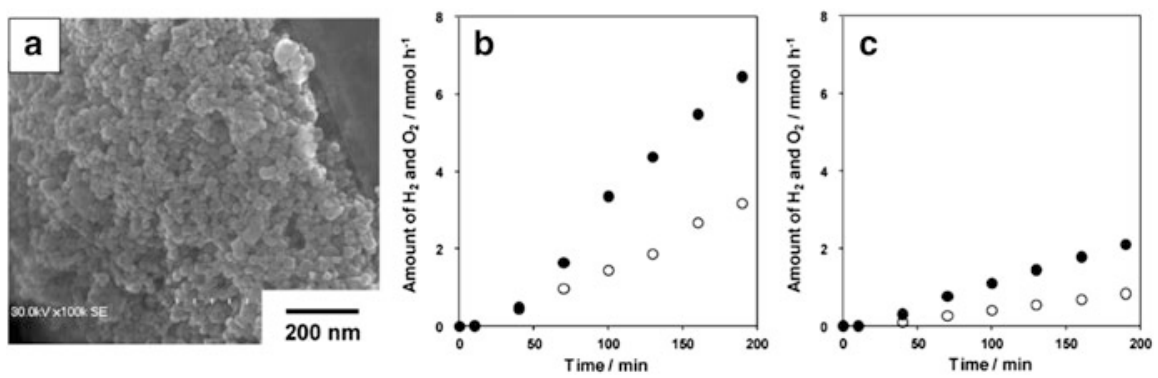

Fig. $19 \mathrm{NiO}-\mathrm{NaTaO}_{3}$ nanoscale photo catalyst. (a) $\mathrm{SEM}$ of $\mathrm{NaTaO}_{3}$, (b, c) $\mathrm{H}_{2} / \mathrm{O}_{2}$ evolution from water with $20 \mathrm{~nm}$ and $50 \mathrm{~nm}$ particles, respectively, under UV irradiation $(\lambda>200 \mathrm{~nm})$ from a 450-W high-pressure mercury lamp (UM-452, Ushio) using $0.3 \mathrm{~g}$ of catalyst. Reproduced from [180] with permission from The Royal Society of Chemistry
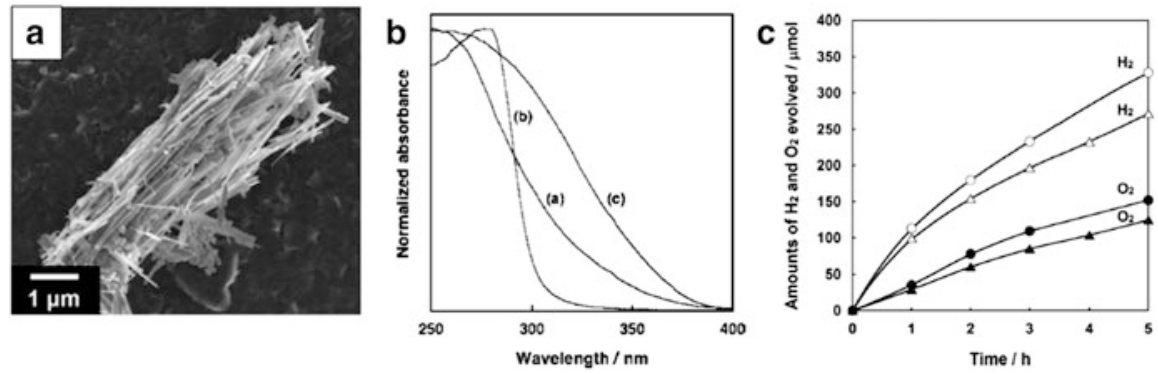

Fig. $20 \mathrm{RuO}_{2}-\mathrm{LiNbO}_{3}$ nanoscale photo catalyst. (a) $\mathrm{SEM}$ of $\mathrm{LiNbO}_{3}$. (b) Optical absorption ( $a$ : $\mathrm{LiNbO}_{3}$-Nanowire, $b$ : $\mathrm{LiNbO}_{3}-\mathrm{Bulk}, c$ : $\mathrm{Nb}_{2} \mathrm{O}_{5}$-Nanowire). (c) $\mathrm{H}_{2} / \mathrm{O}_{2}$ evolution from water with bulk (triangles) and nano $\mathrm{RuO}_{2}-\mathrm{LiNbO}_{3}$ (squares). Conditions: $0.3 \mathrm{~g}$ catalyst, pure water, $370 \mathrm{~mL}$, 400-W high pressure Hg lamp; inner-irradiation cell made of quartz. Reproduced from [142] with permission from The Royal Society of Chemistry

In a third example (Fig. 21), Yan et al. reported overall water splitting with 3 mass $\% \mathrm{RuO}_{2}$-modified $\mathrm{Zn}_{2} \mathrm{GeO}_{4}$ nanorods $(100 \times 150 \mathrm{~nm})$ under $\mathrm{UV}$ light from a $400 \mathrm{~W}$ Hg UV lamp to excite the large band gap $(>4.5 \mathrm{eV})$ of the material. Here, the $\mathrm{H}_{2}$ evolution rate was $17.4 \mu \mathrm{mol} \mathrm{h}{ }^{-1}$ (stoichiometric $\mathrm{O}_{2}$ ) with $100 \mathrm{mg}$ of the catalyst [143]. The lower activity of the bulk material is attributed to surface defects and lower surface area.

The last example consists of 6-30 $\mathrm{nm} \mathrm{SrTiO}{ }_{3}$ nanocrystals with a $3.3 \mathrm{eV}$ indirect band gap (Fig. 22) [181]. After modification with an $\mathrm{NiO}_{x}$ co-catalyst, this system produces $19.4 \mu \mathrm{mol} \mathrm{H}_{2} \mathrm{~g}^{-1} \mathrm{~h}^{-1}$ (with stoichiometric $\mathrm{O}_{2}$ ) from pure water under $>3.2 \mathrm{eV}$ illumination $\left(26.3 \mathrm{~mW} \mathrm{~cm}{ }^{-2}\right)$. The activity of the $30 \mathrm{~nm}$ particles was three times higher than the $6 \mathrm{~nm}$ particles, probably as a result of surface defects in the latter. These defects are visible as the tail in the absorption spectrum. They resulted from the lower preparation temperature of the $6 \mathrm{~nm}$ particles. The $30 \mathrm{~nm}$ particles gave $35 \%$ lower rates for $\mathrm{H}_{2} / \mathrm{O}_{2}$ evolution than the bulk particles (synthesized by solid state reaction). This is attributed to a quantum confinement effect, 

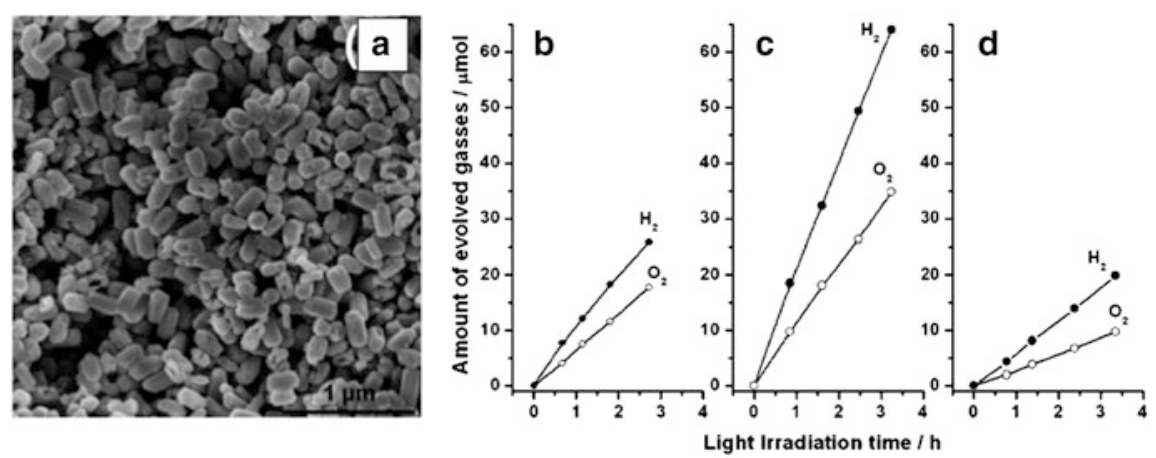

Fig. $21 \mathrm{RuO}_{2}-\mathrm{Zn}_{2} \mathrm{GeO}_{4}$ nanoscale photo catalyst. (a) $\mathrm{SEM}$ of $\mathrm{Zn}_{2} \mathrm{GeO}_{4}$. (b) $\mathrm{H}_{2} / \mathrm{O}_{2}$ evolution from water with particles prepared at $40^{\circ} \mathrm{C}$. (c) Same for particles made at $100^{\circ} \mathrm{C}$. (d) Same for bulk particles from a solid state reaction at $1,300^{\circ} \mathrm{C}$. Conditions: UV irradiation $(\lambda>200 \mathrm{~nm})$ of 0.1 catalyst in pure water with a 400-W high-pressure mercury lamp. Reproduced from [143] with permission from The Royal Society of Chemistry
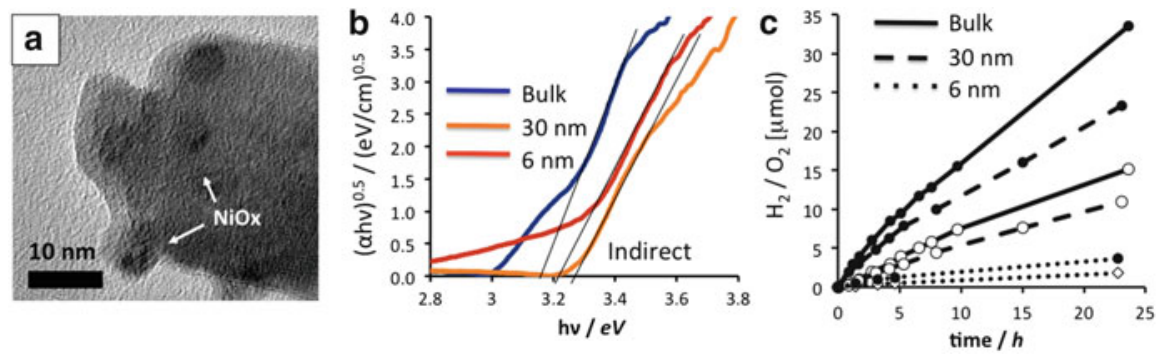

Fig. $22 \mathrm{NiO}-\mathrm{SrTiO}_{3}$ nanoscalephotocatalyst. (a) $\mathrm{SEM}$ of $\mathrm{NiO}_{-} \mathrm{SrTiO}_{3}$. (b) Tauc plots for bulk $(>100 \mathrm{~nm}), 30 \mathrm{~nm}$, and $6 \mathrm{~nm} \mathrm{SrTiO}_{3}$ particles. (c) $\mathrm{H}_{2} / \mathrm{O}_{2}$ evolution from water with $100 \mathrm{mg}$ of catalyst under UV irradiation ( $250-380 \mathrm{~nm}$ at $\sim 26 \mathrm{~mW} \mathrm{~cm}^{-2}$ from a $300 \mathrm{~W}$ Xe lamp). Reproduced from [181]with permission from The American Chemical Society

which increases the band gap of the smaller particles and reduces the absorbed photons.

In 2014, Kudo's group reported the first nanostructured tandem catalyst for overall water splitting [44]. The system employs physical mixtures of $\mathrm{Ru}$-modified $\mathrm{Rh}: \mathrm{SrTiO}_{3}$ and $\mathrm{BiVO}_{4}$ powders in the presence of $\mathrm{FeCl}_{3}$ as a redox shuttle. Whereas 50-70 nm Rh:SrTiO 3 particles gave $16 / 7.5 \mu \mathrm{mol} \mathrm{h}{ }^{-1} \mathrm{H}_{2} / \mathrm{O}_{2}$, $300 \mathrm{~nm}$ particles gave $128 / 64 \mu \mathrm{mol} \mathrm{h}{ }^{-1}$. This inverse particle size dependency of the efficiency suggests sub-optimal charge separation and recombination in the smaller particles. The best system achieved a quantum efficiency of 3.9-4.2\% (at $420 \mathrm{~nm}$ ) and a solar to hydrogen efficiency of $0.1 \%$.

Finally, in 2014, Peidong Yang's group reported direct water splitting from a mesh consisting of $\mathrm{Rh}: \mathrm{SrTiO}_{3}$ and $\mathrm{BiVO}_{4}$ nanowires of 100-200 nm diameter 

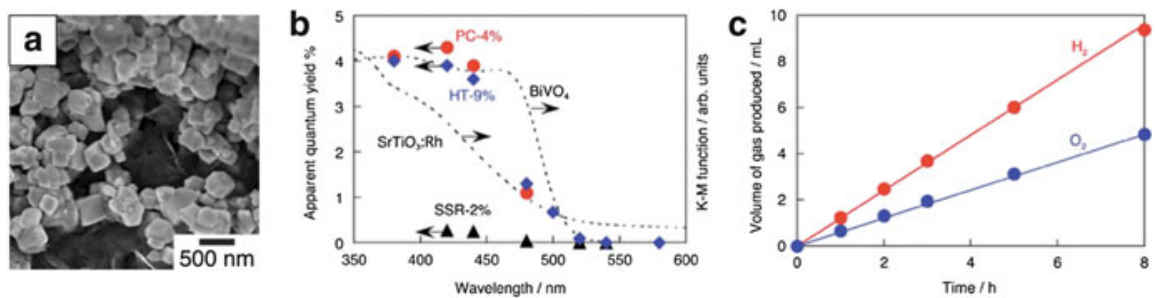

Fig. $23 \mathrm{Sr}: \mathrm{SrTiO}_{3}-\mathrm{Pt} / \mathrm{BiVO}_{4}$ Tandem Photocatalyst system. (a) $\mathrm{SEM}$ of $\mathrm{Rh}: \mathrm{SrTiO}_{3}$. (b) Photoaction spectrum for Tandem system. (c) $\mathrm{H}_{2} / \mathrm{O}_{2}$ evolution under simulated sunlight (AM 1.5). Conditions: $50 \mathrm{mg}$ of catalyst, $2 \mathrm{mM} \mathrm{FeCl}_{3}$ solution. Reproduced from [44] with permission from The Royal Society of Chemistry

(Fig. 23). However, the $\mathrm{H}_{2} / \mathrm{O}_{2}$ evolution rate $\left(<0.2 \mu \mathrm{mol} \mathrm{h}{ }^{-1}\right)$ and the turnover number were too low to designate this process as catalytic [182].

\section{Measuring Photovoltage in Nanoscale Photocatalysts}

The low performance of the examples above emphasizes the need for a better understanding of charge transfer in nanoscale absorbers. Photoelectrochemistry is the most obvious way to probe photochemical charge separation in photocatalyst particles. However, because electrical contact to a working electrode is necessary, measurements need to be conducted on particle films. As noted above, particle mediated charge transport is generally slow, and reduces photocurrents to the microscale (Fig. 24). There is also a substantial potential drop across the film, which obscures the photovoltage of the individual particle junctions. Recently, Domen demonstrated that these charge transfer problems can be alleviated somewhat by evaporating metal electrode layers directly onto particle films [183185]. The photocurrents from photoelectrodes made from Sc: $\mathrm{La}_{5} \mathrm{Ti}_{2} \mathrm{CuS}_{5} \mathrm{O}_{7}$ and $\mathrm{LaTiO}_{2} \mathrm{~N}$ electrodes are strongly enhanced and reach over $-0.5 \mathrm{~mA} \mathrm{~cm} \mathrm{~cm}^{-2}$ $+3.0 \mathrm{~mA} \mathrm{~cm}{ }^{-2}$ for water reduction/oxidation respectively (A.M. 1.5 illumination, at $+0.3 \mathrm{~V} /+1.2 \mathrm{~V}$ vs RHE). This allows for more accurate studies of junction potentials in small particles.

Alternatively, surface photovoltage spectroscopy (SPS) can provide a direct assessment of the photovoltage of particle junctions. In SPS, a semi-transparent Kelvin electrode measures the contact potential difference (CPD) of an illuminated photocatalyst film (Fig. 25) as a function of the excitation energy [187, 188]. The measured photovoltage $(\triangle \mathrm{CPD})$ is produced by the transfer of free charge carriers or polarization of bound charge carrier pairs (polarons) in the sample [189191]. Because the technique relies on the detection of voltage and not current, even small concentrations $\left(<10^{10} \mathrm{~cm}^{-2}\right)$ of charge carriers can be observed [189, 192-197]. This sensitivity exceeds that of photoelectrochemistry by at least 1,000 times. Another advantage of SPS is that it can be performed selectively on solid- 

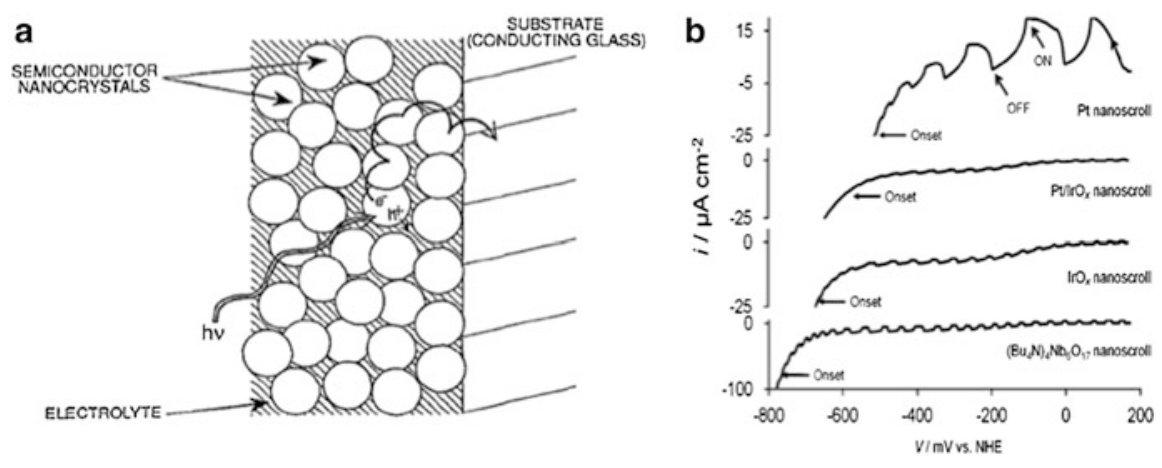

Fig. 24 (a) Charge transport limitation in particulate electrodes. Reproduced from [158] by permission of The Electrochemical Society. (b) Photocurrent scans for niobate nanocrystal films in methanol solution. Reproduced from [186] with permission (2011 Wiley-VCH Verlag GmbH \& Co. KGaA, Weinheim)

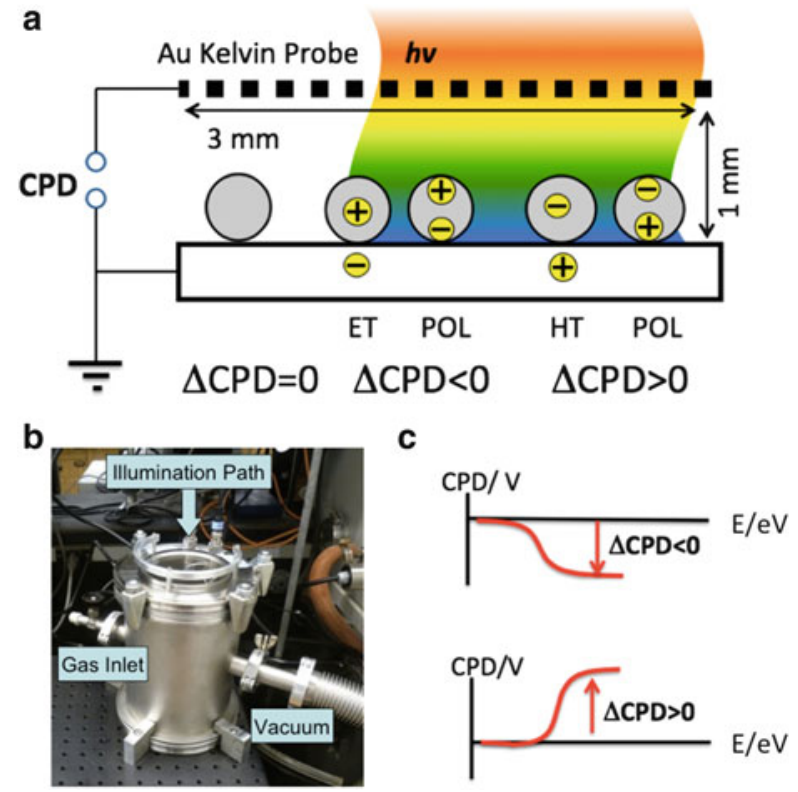

Fig. 25 (a) Geometry of SPV measurement. Contact potential changes are caused by polarization (POL) of electron-hole pairs or by charge transfer (ET/HT) into the substrate. The $\Delta$ CPD value can be interpreted as the open circuit voltage of the sample-substrate junction. (b) SPV Instrument. (c) Example spectra. A negative/positive $\triangle \mathrm{CPD}$ signal corresponds to electron-hole movement towards the substrate. The photo-onset energy provides information about the effective band gap. Reprinted with permission from [190]. Copyright 2014, American Chemical Society 

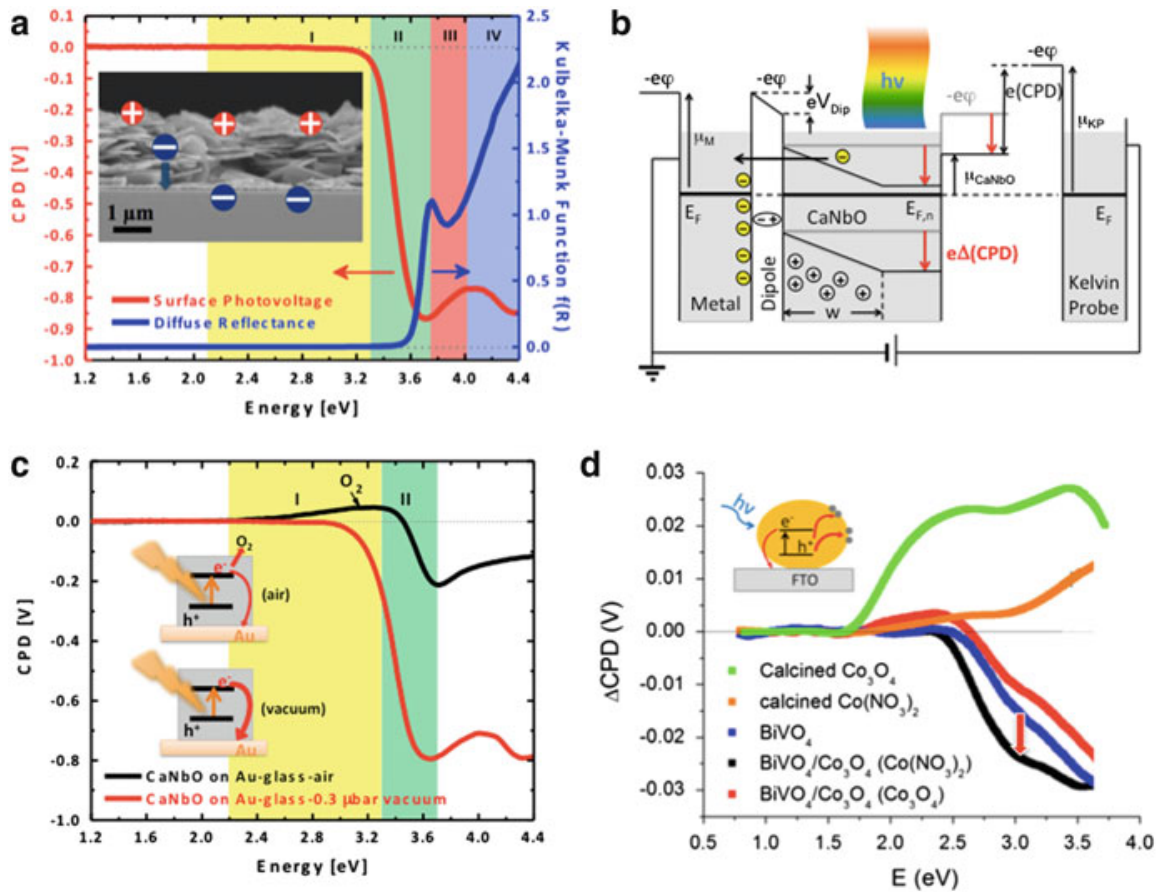

Fig. 26 (a) Surface photovoltage and diffuse reflectance spectra of $\mathrm{HCa}_{2} \mathrm{Nb}_{3} \mathrm{O}_{10}$ nanosheet film on $\mathrm{Au}$ (inset: SEM of film). (b) Energy diagram for the metal-nanosheet-Kelvin probe configuration under band gap illumination. Symbols: e: electron charge, $\varphi$ : electric potential; $\Delta$ CPD: lightinduced contact potential difference change; $w$ : space charge layer width; $\mu_{\mathrm{i}}$ : chemical potential (work function) of $\mathrm{HCa}_{2} \mathrm{Nb}_{3} \mathrm{O}_{10}$, metal substrate, and of Kelvin probe; $V_{\text {Dip }}$ : potential drop from interfacial dipole; $E_{\mathrm{F}}$ : Fermi level (electrochemical potential) in the dark; $E_{\mathrm{Fn}}$ : quasi-Fermi level of electrons under illumination. (c) Photovoltage spectra of nanosheet film in vacuum and air. Reprinted with permission from [189] Copyright 2014, American Chemical Society. (d) SPV spectra of $\mathrm{Co}_{3} \mathrm{O}_{4}, \mathrm{BiVO}_{4}$, and $\mathrm{Co}_{3} \mathrm{O}_{4}-\mathrm{BiVO}_{4}$ on FTO substrate in vacuum (insert: charge transfer direction). Reproduced from [208] with permission from The Royal Society of Chemistry

solid interfaces without the need for a liquid phase or a redox couple. Because the photovoltage is entirely de-coupled from solid-liquid charge transfer, it allows direct measurement of solid-solid junction potentials.

Thomas Dittrich's group has used SPS extensively over the past decade on nanocrystal [198-200], molecular [201-203], and thin film [204] photovoltaics. However, as shown in the following example, SPS is also well suited for the characterization of nanostructured photocatalysts, where it can provide a quantitative understanding of charge transfer at solid-solid and solid-molecule contacts [189]. Figure 26 illustrates this for $\mathrm{HCa}_{2} \mathrm{Nb}_{3} \mathrm{O}_{10}$ nanocrystals, a known large band gap (3.5 eV) water splitting photocatalyst. [205, 206]. The main signal in the SPV spectrum of this compound is negative and corresponds to photochemical electron transfer from $\mathrm{HCa}_{2} \mathrm{Nb}_{3} \mathrm{O}_{10}$ to the gold substrate. The observed photovoltage $(-1.025 \mathrm{~V})$ is controlled by the built-in potential, i.e., $E_{\mathrm{F}}(\mathrm{Au})-$ 
$E_{\mathrm{F}, \mathrm{n}}\left(\mathrm{HCa}_{2} \mathrm{Nb}_{3} \mathrm{O}_{10}=-5.3 \mathrm{eV}\right.$ [207] $-(-3.5 \mathrm{eV})$ [205] $=-1.8 \mathrm{eV}$, of the semiconductor-metal junction, as shown in Fig. 26b. The experimental value is lower because of the low illumination intensity and screening effects in the nanocrystal film.

In the presence of air (Fig. 26c) the negative feature II is decreased and partially replaced by a positive signal at $2.4-3.2 \mathrm{eV}$. This signal belongs to the photoreduction of oxygen. The low energy of the reduction signal suggests that mid-gap surface defects are involved in electron transfer. The ability to observe these states in the SPV spectrum may promote the understanding of photochemical reactions between photocatalyst and molecules. In Fig. 26d the method is applied to the characterization of a contact between $\mathrm{BiVO}_{4}$, a known water oxidation photocatalyst [209], and a $\mathrm{Co}_{3} \mathrm{O}_{4}$ nanoparticle water oxidation co-catalyst. The negative $\triangle \mathrm{CPD}$ signal of $\mathrm{BiVO}_{4}$ alone is produced by electron injection into the FTO substrate. Addition of $\mathrm{a} \mathrm{Co}_{3} \mathrm{O}_{4}$ layer boosts the negative signal by $12 \mathrm{mV}$ (red arrow) because of hole (minority carrier) injection into the cobalt oxide [208]. The boost can be interpreted as the photovoltage of the $\mathrm{Co}_{3} \mathrm{O}_{4}-\mathrm{BiVO}_{4}$ junction. By itself, $\mathrm{p}-\mathrm{Co}_{3} \mathrm{O}_{4}$ has a positive $\Delta \mathrm{CPD}$ signal which stems from hole majority carrier transfer to the FTO substrate. This confirms the p-type character of this oxide. These examples illustrate how SPS can provide useful information about carrier type and charge separation in nanoscale contacts.

\section{Conclusion}

Research activity on nanostructured photocatalysts for solar water splitting has increased significantly over the last 30 years. Nanoscaling has been shown to improve charge extraction from absorbers with low carrier mobility and short carrier lifetimes. For selected metal chalcogenides the quantum size effect has been useful for increasing the stored free energy and for enhancing the rate of charge transfer and photocatalytic proton reduction. It was also shown that the energetics of nanoscale absorbers can be controlled with specifically adsorbed ions. At the same time, it has been found that nanoscaling decreases the ability of an absorber to generate free chemical energy from solar energy. The smaller size of the particles makes electron-hole separation more difficult to achieve because of non-selective interfacial charge transfer and reduced electric fields. Additionally, the larger specific area of nanostructures promotes defect recombination, which reduces the concentration of free charge carriers. These issues limit the photocurrent and the photovoltage that can be generated by the absorber, and with it the solar to hydrogen conversion efficiency. Contemporary research should aim to overcome these problems by developing new chemical methods for surface passivation and selective charge transfer and by more quantitatively assessing photovoltage and surface recombination in nanoparticles. The results from such studies not only benefit solar energy conversion but also promote our understanding of interfaces in general, as relevant to electronics, corrosion science, catalysis, 
materials science, and geology. We already know that useful solar energy conversion is possible at the nanoscale - the photosynthetic systems of bacteria are the earliest examples of nanostructured solar energy conversion devices [68]. Effective artificial devices are sure to follow once we improve our understanding of nanoscale interfaces.

Acknowledgement This material is based upon work supported by the National Science Foundation under CHE - 1152250 and CBET - 1133099. Any opinions, findings, conclusions, or recommendations expressed in this material are those of the author and do not necessarily reflect the views of the National Science Foundation. The author thanks the Research Corporation for Science Advancement for a Scialog award, and Kathryn A. Newton for help with proofreading the manuscript and with obtaining copyrights.

\section{References}

1. Lewis NS, Nocera DG (2006) Powering the planet: chemical challenges in solar energy utilization. Proc Natl Acad Sci U S A 103(43):15729-15735

2. Lewis NS, Crabtree G, Nozik AJ, Wasielewski MR, Alivisatos AP (2005) Basic research needs for solar energy utilization. Department of Energy http://science.energy.gov/bes/ news-and-resources/reports/

3. Green MA, Emery K, Hishikawa Y, Warta W, Dunlop ED (2015) Solar cell efficiency tables (Version 45). Prog Photovolt Res Appl 23(1):1-9

4. Peharz G, Dimroth F, Wittstadt U (2007) Solar hydrogen production by water splitting with a conversion efficiency of 18\%. Int J Hydrogen Energy 32(15):3248-3252

5. Nocera DG (2012) The Artificial Leaf. Acc Chem Res 45(5):767-776

6. Reece SY, Hamel JA, Sung K, Jarvi TD, Esswein AJ, Pijpers JJH, Nocera DG (2011) Wireless solar water splitting using silicon-based semiconductors and Earth-abundant catalysts. Science 334(6056):645-648

7. Luo J, Im J-H, Mayer MT, Schreier M, Nazeeruddin MK, Park N-G, Tilley SD, Fan HJ, Grätzel M (2014) Water photolysis at $12.3 \%$ efficiency via perovskite photovoltaics and Earth-abundant catalysts. Science 345(6204):1593-1596

8. Gratzel M, Park NG (2014) Organometal halide perovskite photovoltaics: a diamond in the rough. Nano 9(5):1440002-1440009

9. Walter MG, Warren EL, McKone JR, Boettcher SW, Mi QX, Santori EA, Lewis NS (2010) Solar water splitting cells. Chem Rev 110(11):6446-6473

10. Khaselev O, Turner JA (1998) A monolithic photovoltaic-photoelectrochemical device for hydrogen production via water splitting. Science 280(5362):425-427

11. Bolton JR, Strickler SJ, Connolly JS (1985) Limiting and realizable efficiencies of solar photolysis of water. Nature 316(6028):495-500

12. Varghese OK, Grimes CA (2008) Appropriate strategies for determining the photoconversion efficiency of water photo electrolysis cells: a review with examples using titania nanotube array photoanodes. Sol Energy Mat Sol C 92(4):374-384

13. Sathre R, Scown CD, Morrow WR, Stevens JC, Sharp ID, Ager JW, Walczak K, Houle FA, Greenblatt JB (2014) Life-cycle net energy assessment of large-scale hydrogen production via photoelectrochemical water splitting. Energy Environ Sci 7:3264-3278

14. Ronge J, Bosserez T, Martel D, Nervi C, Boarino L, Taulelle F, Decher G, Bordiga S, Martens JA (2014) Monolithic cells for solar fuels. Chem Soc Rev 43:7963-7981

15. Osterloh FE (2008) Inorganic materials as catalysts for photochemical splitting of water. Chem Mater 20(1):35-54 
16. Maeda K (2013) Z-Scheme water splitting using two different semiconductor photocatalysts. ACS Catal 3(7):1486-1503

17. Kudo A (2011) Z-Scheme photocatalyst systems for water splitting under visible light irradiation. MRS Bull 36(1):32-38

18. Maeda K, Teramura K, Saito N, Inoue Y, Kobayashi H, Domen K (2006) Overall water splitting using (oxy)nitride photocatalysts. Pure Appl Chem 78(12):2267-2276

19. Rajeshwar K (2007) Hydrogen generation at irradiated oxide semiconductor-solution interfaces. J Appl Electrochem 37(7):765-787

20. Maeda K (2011) Photocatalytic water splitting using semiconductor particles: history and recent developments. J Photoch Photobio C 12(4):237-268

21. Maeda K, Domen K (2007) New non-oxide photocatalysts designed for overall water splitting under visible light. J Phys Chem C 111(22):7851-7861

22. Kudo A, Miseki Y (2009) Heterogeneous photocatalyst materials for water splitting. Chem Soc Rev 38(1):253-278

23. Abe R (2010) Recent progress on photocatalytic and photoelectrochemical water splitting under visible light irradiation. J Photoch Photobio C 11(4):179-209

24. Osterloh FE, Parkinson BA (2011) Recent developments in solar water splitting photocatalysis. MRS Bull 36(1):17-22

25. Pinaud BA, Benck JD, Seitz LC, Forman AJ, Chen ZB, Deutsch TG, James BD, Baum KN, Baum GN, Ardo S, Wang HL, Miller E, Jaramillo TF (2013) Technical and economic feasibility of centralized facilities for solar hydrogen production via photocatalysis and photoelectrochemistry. Energy Environ Sci 6(7):1983-2002

26. James BD, Baum GN, Perez J, Baum KN http://www1.eere.energy.gov/hydrogenandfuelcells/ pdfs/pec_technoeconomic_analysis.pdf

27. Bard AJ, Fox MA (1995) Artificial photosynthesis - solar splitting of water to hydrogen and oxygen. Acc Chem Res 28(3):141-145

28. Mills A, LeHunte S (1997) An overview of semiconductor photocatalysis. J Photoch Photobio A 108(1):1-35

29. Nozik AJ (1978) Photoelectrochemistry - applications to solar-energy conversion. Ann Rev Phys Chem 29:189-222

30. Memming R (1994) Photoinduced charge-transfer processes at semiconductor electrodes and particles. Electron Transfer I 169:105-181

31. Krol R (2012) Principles of photoelectrochemical cells. In: van de Krol R, Grätzel M (eds) Photoelectrochemical hydrogen production, vol 102. Springer, USA, pp 13-67

32. Kato H, Asakura K, Kudo A (2003) Highly efficient water splitting into H-2 and O-2 over lanthanum-doped $\mathrm{NaTaO}_{3}$ photocatalysts with high crystallinity and surface nanostructure. J Am Chem Soc 125(10):3082-3089

33. Ohno T, Bai L, Hisatomi T, Maeda K, Domen K (2012) Photocatalytic water splitting using modified $\mathrm{GaN}: \mathrm{ZnO}$ solid solution under visible light: long-time operation and regeneration of activity. J Am Chem Soc 134(19):8254-8259

34. Maeda K, Teramura K, Lu DL, Takata T, Saito N, Inoue Y, Domen K (2006) Characterization of Rh-Cr mixed-oxide nanoparticles dispersed on $(\mathrm{Ga} 1-\mathrm{xZnx})(\mathrm{N} 1-\mathrm{xOx})$ as a cocatalyst for visible-light-driven overall water splitting. J Phys Chem B 110(28):13753-13758

35. Maeda K, Teramura K, Lu DL, Takata T, Saito N, Inoue Y, Domen K (2006) Photocatalyst releasing hydrogen from water - enhancing catalytic performance holds promise for hydrogen production by water splitting in sunlight. Nature 440(7082):295-295

36. Zou ZG, Ye JH, Sayama K, Arakawa H (2001) Direct splitting of water under visible light irradiation with an oxide semiconductor photocatalyst. Nature 414(6864):625-627

37. Zou ZG, Arakawa H (2003) Direct water splitting into H-2 and O-2 under visible light irradiation with a new series of mixed oxide semiconductor photocatalysts. J Photoch Photobio A 158(2-3):145-162 
38. Liao L, Zhang Q, Su Z, Zhao Z, Wang Y, Li Y, Lu X, Wei D, Feng G, Yu Q, Cai X, Zhao J, Ren Z, Fang H, Robles-Hernandez F, Baldelli S, Bao J (2014) Efficient solar water-splitting using a nanocrystalline $\mathrm{CoO}$ photocatalyst. Nat Nano 9(1):69-73

39. Hara M, Kondo T, Komoda M, Ikeda S, Shinohara K, Tanaka A, Kondo JN, Domen K (1998) $\mathrm{Cu}_{2} \mathrm{O}$ as a photocatalyst for overall water splitting under visible light irradiation. Chem Commun 3:357-358

40. de Jongh PE, Vanmaekelbergh D, Kelly JJ (1999) $\mathrm{Cu}_{2} \mathrm{O}$ : a catalyst for the photochemical decomposition of water? Chem Commun 12:1069-1070

41. Malingowski AC, Stephens PW, Huq A, Huang QZ, Khalid S, Khalifah PG (2012) Substitutional mechanism of $\mathrm{Ni}$ into the wide-band-gap semiconductor in $\mathrm{TaO}_{4}$ and its implications for water splitting activity in the wolframite structure type. Inorg Chem 51(11):6096-6103

42. Duonghong D, Borgarello E, Gratzel M (1981) Dynamics of light-induced water cleavage in colloidal systems. J Am Chem Soc 103(16):4685-4690

43. Bard AJ (1979) Photoelectrochemistry and heterogeneous photocatalysis at semiconductors. J Photochem 10(1):59-75

44. Kato H, Sasaki Y, Shirakura N, Kudo A (2013) Synthesis of highly active rhodium-soped $\mathrm{SrTiO}_{3}$ powders in Z-scheme systems for visible-light-driven photocatalytic overall water splitting. J Mater Chem A 1(39):12327-12333

45. Hu S, Shaner MR, Beardslee JA, Lichterman M, Brunschwig BS, Lewis NS (2014) Amorphous $\mathrm{TiO}_{2}$ coatings stabilize $\mathrm{Si}, \mathrm{GaAs}$, and $\mathrm{GaP}$ photoanodes for efficient water oxidation. Science 344(6187):1005-1009

46. Paracchino A, Laporte V, Sivula K, Graetzel M, Thimsen E (2011) Highly active oxide photocathode for photoelectrochemical water reduction. Nat Mater 10(6):456-461

47. Joshi UA, Palasyuk A, Arney D, Maggard PA (2010) Semiconducting oxides to facilitate the conversion of solar energy to chemical fuels. J Phys Chem Lett 1(18):2719-2726

48. Woodhouse M, Parkinson BA (2008) Combinatorial discovery and optimization of a complex oxide with water photoelectrolysis activity. Chem Mater 20(7):2495-2502

49. Woodhouse M, Herman GS, Parkinson BA (2005) Combinatorial approach to identification of catalysts for the photoelectrolysis of water. Chem Mater 17(17):4318-4324

50. Woodhouse M, Parkinson BA (2009) Combinatorial approaches for the identification and optimization of oxide semiconductors for efficient solar photoelectrolysis. Chem Soc Rev 38(1):197-210

51. Jaramillo TF, Baeck SH, Kleiman-Shwarsctein A, Choi KS, Stucky GD, McFarland EW (2005) Automated electrochemical synthesis and photoelectrochemical characterization of Zn1-xCoxO thin films for solar hydrogen production. J Comb Chem 7(2):264-271

52. Katz JE, Gingrich TR, Santori EA, Lewis NS (2009) Combinatorial synthesis and highthroughput photopotential and photocurrent screening of mixed-metal oxides for photoelectrochemical water splitting. Energy Environ Sci 2(1):103-112

53. Dingle R, Wiegmann W, Henry CH (1974) Quantum states of confined carriers in very thin AlxGa1-xAs-GaAs-AlxGa1-xAs heterostructures. Phys Rev Lett 33(14):827-830

54. Henglein A (1982) Photo-degradation and fluorescence of colloidal-cadmium sulfide in aqueous-solution. Phys Chem Chem Phys 86(4):301-305

55. Fojtik A, Weller H, Koch U, Henglein A (1984) Photo-chemistry of colloidal metal sulfides. 8. Photo-physics of extremely small CDS particle S - Q-state CDS and magic agglomeration numbers. Phys Chem Chem Phys 88(10):969-977

56. Brus LE (1983) A simple-model for the ionization-potential, electron-affinity, and aqueous redox potentials of small semiconductor crystallites. J Chem Phys 79(11):5566-5571

57. Vayssieres L (2009) On solar hydrogen \& nanotechnology. Wiley, Singapore/Hoboken, $\mathrm{p} x x i, 680 \mathrm{pp}, 16 \mathrm{p}$

58. Hoertz PG, Mallouk TE (2005) Light-to-chemical energy conversion in lamellar solids and thin films. Inorg Chem 44(20):6828-6840

59. Hagfeldt A, Gratzel M (1995) Light-induced redox reactions in nanocrystalline systems. Chem Rev 95(1):49-68 
60. Zhu JF, Zach M (2009) Nanostructured materials for photocatalytic hydrogen production. Curr Opin Colloid Interface Sci 14(4):260-269

61. Kamat PV (2007) Meeting the clean energy demand: nanostructure architectures for solar energy conversion. J Phys Chem C 111(7):2834-2860

62. Kamat PV, Dimitrijevic NM (1990) Colloidal semiconductors as photocatalysts for solarenergy conversion. Sol Energy 44(2):83-98

63. Kamat PV, Tvrdy K, Baker DR, Radich JG (2010) Beyond photovoltaics: semiconductor nanoarchitectures for liquid-junction solar cells. Chem Rev 110(11):6664-6688

64. Zhang JZ (2011) Metal oxide nanomaterials for solar hydrogen generation from photoelectrochemical water splitting. MRS Bull 36(1):48-55

65. Foley JM, Price MJ, Feldblyum JI, Maldonado S (2012) Analysis of the operation of thin nanowire photoelectrodes for solar energy conversion. Energy Environ Sci 5(1):5203-5220

66. Jaegermann W, Tributsch H (1988) Interfacial properties of semiconducting transition-metal chalcogenides. Prog Surf Sci 29(1-2):1-167

67. van de Krol R, Liang YQ, Schoonman J (2008) Solar hydrogen production with nanostructured metal oxides. J Mater Chem 18(20):2311-2320

68. Umena Y, Kawakami K, Shen JR, Kamiya N (2011) Crystal structure of oxygen-evolving photosystem II at a resolution of $1.9 \AA$. Nature 473(7345):55-U65

69. Boddy PJ (1968) Oxygen evolution on semiconducting $\mathrm{TIO}_{2}$. J Electrochem Soc 115(2):199

70. Freund T, Gomes WP (1970) Electrochemical methods for investigating catalysis by semiconductors. Catal Rev 3(1):1-36

71. Fujishima A, Honda K (1971) Studies on photosensitive electrode reactions. 3. Electrochemical evidence for mechanism of primary stage of photosynthesis. B Chem Soc Jpn 44(4):1148-1150

72. Fujishima A, Honda K (1972) Electrochemical photolysis of water at a semiconductor electrode. Nature 238(5358):37-38

73. Henglein A (1989) Small-particle research - physicochemical properties of extremely small colloidal metal and semiconductor particles. Chem Rev 89(8):1861-1873

74. Kalyanasundaram K, Gratzel M (1979) Cyclic cleavage of water into H-2 and O-2 by visiblelight with coupled redox catalysts. Angew Chem Int Ed Engl 18(9):701-702

75. Mills A, Porter G (1982) Photosensitized dissociation of water using dispersed suspensions of N-type semiconductors. J Chem Soc Faraday T I 78:3659-3669

76. Nozik AJ (1977) Photochemical diodes. Appl Phys Lett 30(11):567-569

77. Würfel P (2005) Physics of solar cells. Wiley-VCH, Weinheim, p 244

78. Berger LI (2008) Optical properties of selected inorganic and organic solids. In: Lide DR (ed) CRC handbook of chemistry and physics, vol 88. CRC/Taylor and Francis, Boca Raton

79. Maiolo JR, Atwater HA, Lewis NS (2008) Macroporous silicon as a model for silicon wire array solar cells. J Phys Chem C 112(15):6194-6201

80. Berger LI (2008) Properties of semiconductors. In: Lide DR (ed) CRC handbook of chemistry and physics, vol 88. CRC/Taylor and Francis, Boca Raton

81. Huda MN, Al-Jassim MM, Turner JA (2011) Mott insulators: an early selection criterion for materials for photoelectrochemical H(2) production. J Renew Sustain Energy 3(5):0531011-053101-10

82. Cox PA (2010) Transition metal oxides: an introduction to their electronic structure and properties. Clarendon/Oxford University Press, Oxford/New York

83. Sabio EM, Chamousis RL, Browning ND, Osterloh FE (2012) Correction: photocatalytic water splitting with suspended calcium niobium oxides: why nanoscale is better than bulk - a kinetic analysis. J Phys Chem C 116(35):19051-19051

84. Sabio EM, Chamousis RL, Browning ND, Osterloh FE (2012) Photocatalytic water splitting with suspended calcium niobium oxides: why nanoscale is better than bulk - a kinetic analysis. J Phys Chem C 116(4):3161-3170

85. Laser D, Bard AJ (1976) Semiconductor electrodes. 9. digital-simulation of relaxation of photogenerated free carriers and photocurrents. J Electrochem Soc 123(12):1837-1842 
86. Morrison SR (1980) Electrochemistry at semiconductor and oxidized metal electrodes. Plenum, New York, p xiv, 401

87. Pleskov YV, Gurevich YY (1986) Semiconductor photoelectrochemistry. Consultants Bureau, New York, p xxv, 422

88. Salvador P (2001) Semiconductors' photoelectrochemistry: a kinetic and thermodynamic analysis in the light of equilibrium and nonequilibrium models. J Phys Chem B 105(26): $6128-6141$

89. Townsend TK, Sabio EM, Browning ND, Osterloh FE (2011) Photocatalytic water oxidation with suspended alpha- $\mathrm{Fe}_{2} \mathrm{O}_{3}$ particles - effects of nanoscaling. Energy Env Sci 4:4270-4275

90. de Almeida JS, Ahuja R (2006) Electronic and optical properties of $\mathrm{RuO}_{2}$ and $\mathrm{IrO}_{2}$. Phys Rev B 3(16)

91. Frame FA, Townsend TK, Chamousis RL, Sabio EM, Dittrich T, Browning ND, Osterloh FE (2011) Photocatalytic water oxidation with non-sensitized $\mathrm{IrO}_{2}$ nanocrystals under visible and UV light. J Am Chem Soc 133(19):7264-7267

92. Yoffe AD (2001) Semiconductor quantum dots and related systems: electronic, optical, luminescence and related properties of low dimensional systems. Adv Phys 50(1):1-208

93. Gerischer H (1990) The impact of semiconductors on the concepts of electrochemistry. Electrochim Acta 35(11-12):1677-1699

94. Marcus RA (1964) Chemical + electrochemical electron-transfer theory. Ann Rev Phys Chem 15:155-196

95. Sant PA, Kamat PV (2002) Interparticle electron transfer between size-quantized CdS and $\mathrm{TiO}_{2}$ semiconductor nanoclusters. Phys Chem Chem Phys 4(2):198-203

96. Robel I, Kuno M, Kamat PV (2007) Size-dependent electron injection from excited CdSe quantum dots into $\mathrm{TiO}_{2}$ nanoparticles. J Am Chem Soc 129(14):4136-4137

97. Tvrdy K, Frantsuzov PA, Kamat PV (2011) Photoinduced electron transfer from semiconductor quantum dots to metal oxide nanoparticles. PNAS 108(1):29-34

98. Holmes MA, Townsend TK, Osterloh FE (2012) Quantum confinement controlled photocatalytic water splitting by suspended CdSe nanocrystals. Chem Commun 48(3): 371-373

99. Zhao J, Holmes MA, Osterloh FE (2013) Quantum confinement controls photocatalysis - a free energy analysis for photocatalytic proton reduction at CdSe nanocrystals. ACS Nano 7(5):4316-4325

100. Rogach AL, Kornowski A, Gao MY, Eychmuller A, Weller H (1999) Synthesis and characterization of a size series of extremely small thiol-stabilized CdSe nanocrystals. J Phys Chem B 103(16):3065-3069

101. Bard AJ, Faulkner LR (2001) Electrochemical methods: fundamentals and applications. 2nd edn. Wiley, New York, p xxi, 833

102. Waller M, Townsend TK, Zhao J, Sabio EM, Chamousis RL, Browning ND, Osterloh FE (2012) Single-crystal tungsten oxide nanosheets: photochemical water oxidation in the quantum confinement regime. Chem Mater 24(4):698-704

103. Sambur JB, Novet T, Parkinson BA (2010) Multiple exciton collection in a sensitized photovoltaic system. Science 330(6000):63-66

104. Semonin OE, Luther JM, Choi S, Chen HY, Gao JB, Nozik AJ, Beard MC (2011) Peak external photocurrent quantum efficiency exceeding $100 \%$ via MEG in a quantum dot solar cell. Science 334(6062):1530-1533

105. Nozik AJ (2002) Quantum dot solar cells. Phys E Low Dimens Syst Nanostruct 14(1-2): $115-120$

106. Kavan L, Gratzel M, Gilbert SE, Klemenz C, Scheel HJ (1996) Electrochemical and photoelectrochemical investigation of single-crystal anatase. J Am Chem Soc 118(28): 6716-6723

107. Khan SUM, Akikusa J (1999) Photoelectrochemical splitting of water at nanocrystalline n- $\mathrm{Fe}_{2} \mathrm{O}_{3}$ thin-film electrodes. J Phys Chem B 103(34):7184-7189 
108. Atkinson RJ, Posner AM, Quirk JP (1967) Adsorption of potential-determining ions at ferric oxide-aqueous electrolyte interface. J Phys Chem 71(3):550-558

109. Brown GE, Henrich VE, Casey WH, Clark DL, Eggleston C, Felmy A, Goodman DW, Gratzel M, Maciel G, McCarthy MI, Nealson KH, Sverjensky DA, Toney MF, Zachara JM (1999) Metal oxide surfaces and their interactions with aqueous solutions and microbial organisms. Chem Rev 99(1):77-174

110. Hingston FJ, Atkinson RJ, Posner AM, Quirk JP (1967) Specific adsorption of anions. Nature 215(5109):1459-1461

111. Meissner D, Memming R, Kastening B (1988) Photoelectrochemistry of cadmium-sulfide. 1. Reanalysis of photocorrosion and flat-band potential. J Phys Chem 92(12):3476-3483

112. Ginley DS, Butler MA (1978) Flatband potential of cadmium-sulfide (Cds) photoanodes and its dependence on surface ion effects. J Electrochem Soc 125(12):1968-1974

113. Frese KW, Canfield DG (1984) Adsorption of hydroxide and sulfide ions on single-crystal n-CdSe electrodes. J Electrochem Soc 131(11):2614-2618

114. Lincot D, Vedel J (1988) Adsorption of telluride ions on cadmium telluride - consequences for photoelectrochemical cells. J Phys Chem 92(14):4103-4110

115. Minoura H, Watanabe T, Oki T, Tsuiki M (1977) Effects of dissolved Cd2+ and S2- ions on flatband potential of CdS electrode in aqueous-solution. Jpn J Appl Phys 16(5):865-866

116. Singh P, Singh R, Gale R, Rajeshwar K, Dubow J (1980) Surface-charge and specific ion adsorption effects in photoelectrochemical devices. J Appl Phys 51(12):6286-6291

117. Butler MA, Ginley GS (1978) Prediction of flatband potentials at semiconductor-electrolyte interfaces from atomic electronegativies. J Electrochem Soc 125(2):228-232

118. Bard AJ, Faulkner LR (2001) Electrochemical methods: fundamentals and applications, 2nd edn. Wiley, New York, p 60

119. Vanysek P (2008) Electrochemical series. In: CRC handbook of chemistry and physics, vol 88. CRC/Taylor and Francis, Boca Raton

120. Bard AJ, Faulkner LR (2001) Electrochemical methods: fundamentals and applications, 2nd edn, Wiley, New York, p 550

121. Grahame DC (1947) The electrical double layer and the theory of electrocapillarity. Chem Rev 41(3):441-501

122. Mayer JM (2004) Proton-coupled electron transfer: a reaction chemist's view. Ann Rev Phys Chem 55:363-390

123. Chamousis RL, Osterloh FE (2014) Use of potential determining ions to control energetics and photochemical charge transfer of a nanoscale water splitting photocatalyst. Energy Envi Sci 7(2):736-743

124. Nozik AJ, Memming R (1996) Physical chemistry of semiconductor-liquid interfaces. J Phys Chem 100(31):13061-13078

125. Miller RJD, Memming R (2008) Fundamentals in photoelectrochemistry. In: Archer MD, Nozik AJ (eds) Nanostructured and photoelectrochemical systems for solar photon conversion, vol 3. Imperial College Press, London

126. Chmiel G, Gerischer H (1990) Photoluminescence at a semiconductor electrolyte contact around and beyond the flat-band potential. J Phys Chem 94(4):1612-1619

127. Klahr BM, Hamann TW (2011) Current and voltage limiting processes in thin film hematite electrodes. J Phys Chem C 115(16):8393-8399

128. Tan MX, Laibinis PE, Nguyen ST, Kesselman JM, Stanton CE, Lewis NS (1994) Principles and applications of semiconductor photoelectrochemistry. In: Progress in inorganic chemistry, Wiley, New York, vol 41. pp 21-144

129. Cowan AJ, Tang JW, Leng WH, Durrant JR, Klug DR (2010) Water splitting by nanocrystalline $\mathrm{TiO}_{2}$ in a complete photoelectrochemical cell exhibits efficiencies limited by charge recombination. J Phys Chem C 114(9):4208-4214

130. Tang JW, Durrant JR, Klug DR (2008) Mechanism of photocatalytic water splitting in TiO (2). Reaction of water with photoholes, importance of charge carrier dynamics, and evidence for four-hole chemistry. J Am Chem Soc 130(42):13885-13891 
131. McCrory CCL, Jung SH, Peters JC, Jaramillo TF (2013) Benchmarking heterogeneous electrocatalysts for the oxygen evolution reaction. J Am Chem Soc 135(45):16977-16987

132. Popczun EJ, McKone JR, Read CG, Biacchi AJ, Wiltrout AM, Lewis NS, Schaak RE (2013) Nanostructured nickel phosphide as an electrocatalyst for the hydrogen evolution reaction. J Am Chem Soc 135(25):9267-9270

133. Popczun EJ, Read CG, Roske CW, Lewis NS, Schaak RE (2014) Highly active electrocatalysis of the hydrogen evolution reaction by cobalt phosphide nanoparticles. Angew Chem 126(21):5531-5534

134. Lewis NS (2005) Chemical control of charge transfer and recombination at semiconductor photoelectrode surfaces. Inorg Chem 44(20):6900-6911

135. Shockley W, Queisser HJ (1961) Detailed balance limit of efficiency of p-n junction solar cells. J Appl Phys 32(3):510-519

136. Lewis NS (1990) Mechanistic studies of light-induced charge separation at semiconductor liquid interfaces. Acc Chem Res 23(6):176-183

137. Lewis NS (2001) Frontiers of research in photoelectrochemical solar energy conversion. J Electroanal Chem 508(1-2):1-10

138. Yablonovitch E, Allara DL, Chang CC, Gmitter T, Bright TB (1986) Unusually low surface recombination velocity on silicon and germanium surfaces. Phys Rev Lett 57(2):249-252

139. Diebold U (2003) The surface science of titanium dioxide. Surf Sci Rep 48(5-8):53-229

140. Cummings CY, Marken F, Peter LM, Tahir AA, Wijayantha KGU (2012) Kinetics and mechanism of light-driven oxygen evolution at thin film alpha- $\mathrm{Fe}_{2} \mathrm{O}_{3}$ electrodes. Chem Commun 48(14):2027-2029

141. Arakawa $\mathrm{H}$ (2002) Water photolysis by $\mathrm{TiO}_{2}$ particles-significant effect of $\mathrm{Na}_{2} \mathrm{CO}_{3}$ addition on water splitting. In: Kaneko M, Okura I (eds) Photocatalysis science and technology. Springer, New York, pp 235-248

142. Saito K, Koga K, Kudo A (2011) Lithium niobate nanowires for photocatalytic water splitting. Dalton Trans 40(15):3909-3913

143. Yan SC, Wan LJ, Li ZS, Zou ZG (2011) Facile temperature-controlled synthesis of hexagonal $\mathrm{Zn}(2) \mathrm{GeO}(4)$ nanorods with different aspect ratios toward improved photocatalytic activity for overall water splitting and photoreduction of $\mathrm{CO}(2)$. Chem Commun 47(19):5632-5634

144. Pala RA, Leenheer AJ, Lichterman M, Atwater HA, Lewis NS (2014) Measurement of minority-carrier diffusion lengths using wedge-shaped semiconductor photoelectrodes. Energy Environ Sci 7(10):3424-3430

145. Pendlebury SR, Cowan AJ, Barroso M, Sivula K, Ye JH, Gratzel M, Klug DR, Tang JW, Durrant JR (2012) Correlating long-lived photogenerated hole populations with photocurrent densities in hematite water oxidation photoanodes. Energy Environ Sci 5(4):6304-6312

146. Hagedorn K, Forgacs C, Collins S, Maldonado S (2010) Design considerations for nanowire heterojunctions in solar energy conversion/storage applications. J Phys Chem C 114(27): 12010-12017

147. Maruyama M, Iwase A, Kato H, Kudo A, Onishi H (2009) Time-resolved infrared absorption study of $\mathrm{NaTaO}_{3}$ photocatalysts doped with alkali earth metals. J Phys Chem C 113(31): 13918-13923

148. Garnett EC, Yang PD (2008) Silicon nanowire radial p-n junction solar cells. J Am Chem Soc 130(29):9224

149. Wu P, Wang J, Zhao J, Guo L, Osterloh FE (2014) Structure defects in g-C3N4 limit visible light driven hydrogen evolution and photovoltage. J Mater Chem A 2(47):20338-20344

150. Osterloh FE (2014) Boosting the efficiency of suspended photocatalysts for overall water splitting. J Phys Chem Lett 5(15):2510-2511

151. Le Formal F, Tetreault N, Cornuz M, Moehl T, Gratzel M, Sivula K (2011) Passivating surface states on water splitting hematite photoanodes with alumina overlayers. Chem Sci 2(4):737-743

152. Spray RL, McDonald KJ, Choi K-S (2011) Enhancing photoresponse of nanoparticulate alpha- $\mathrm{Fe}_{2} \mathrm{O}_{3}$ electrodes by surface composition tuning. J Phys Chem C 115(8):3497-3506 
153. Liang YQ, Tsubota T, Mooij LPA, van de Krol R (2011) Highly improved quantum efficiencies for thin film $\mathrm{BiVO}_{4}$ photoanodes. J Phys Chem C 115(35):17594-17598

154. Zhong DK, Choi S, Gamelin DR (2011) Near-complete suppression of surface recombination in solar photoelectrolysis by "Co-Pi" catalyst-modified W:BiVO4. J Am Chem Soc 133(45): 18370-18377

155. Osterloh FE (2014) Maximum theoretical efficiency limit of photovoltaic devices: effect of band structure on excited state entropy. J Phys Chem Lett 2014:3354-3359

156. Gerischer H (1966) Electrochemical behavior of semiconductors under illumination. J Electrochem Soc 113(11):1174-1182

157. Polman A, Atwater HA (2012) Photonic design principles for ultrahigh-efficiency photovoltaics. Nat Mater 11(3):174-177

158. Hodes G, Howell IDJ, Peter LM (1992) Nanocrystalline photoelectrochemical cells - a new concept in photovoltaic cells. J Electrochem Soc 139(11):3136-3140

159. Cesar I, Sivula K, Kay A, Zboril R, Graetzel M (2009) Influence of feature size, film thickness, and silicon doping on the performance of nanostructured hematite photoanodes for solar water splitting. J Phys Chem C 113(2):772-782

160. Oregan B, Moser J, Anderson M, Gratzel M (1990) Vectorial electron injection into transparent semiconductor membranes and electric-field effects on the dynamics of light-induced charge separation. J Phys Chem 94(24):8720-8726

161. Dloczik L, Ileperuma O, Lauermann I, Peter LM, Ponomarev EA, Redmond G, Shaw NJ, Uhlendorf I (1997) Dynamic response of dye-sensitized nanocrystalline solar cells: characterization by intensity-modulated photocurrent spectroscopy. J Phys Chem B 101(49): 10281-10289

162. Giebink NC, Wiederrecht GP, Wasielewski MR, Forrest SR (2011) Thermodynamic efficiency limit of excitonic solar cells. Phys Rev B 83(19):195326-1-195326-6

163. Miseki Y, Kato H, Kudo A (2009) Water splitting into $\mathrm{H}_{2}$ and $\mathrm{O}_{2}$ over niobate and titanate photocatalysts with (111) plane-type layered perovskite structure. Energy Environ Sci 2(3): 306-314

164. Matsumoto Y, Ida S, Inoue T (2008) Photodeposition of metal and metal oxide at the TiOx nanosheet to observe the photocatalytic active site. J Phys Chem C 112(31):11614-11616

165. Sabio EM, Chi M, Browning ND, Osterloh FE (2010) Charge separation in a niobate nanosheet photocatalyst studied with photochemical labeling. Langmuir 26(10):7254-7261

166. Li RG, Han HX, Zhang FX, Wang DG, Li C (2014) Highly efficient photocatalysts constructed by rational assembly of dual-cocatalysts separately on different facets of $\mathrm{BiVO}_{4}$. Energy Environ Sci 7(4):1369-1376

167. Giocondi JL, Rohrer GS (2001) Spatially selective photochemical reduction of silver on the surface of ferroelectric barium titanate. Chem Mater 13(2):241-242

168. Yang SY, Seidel J, Byrnes SJ, Shafer P, Yang CH, Rossell MD, Yu P, Chu YH, Scott JF, Ager JW, Martin LW, Ramesh R (2010) Above-bandgap voltages from ferroelectric photovoltaic devices. Nat Nanotechnol 5(2):143-147

169. Li L, Salvador PA, Rohrer GS (2014) Photocatalysts with internal electric fields. Nanoscale 6(1):24-42

170. Abdi FF, Han LH, Smets AHM, Zeman M, Dam B, van de Krol R (2013) Efficient solar water splitting by enhanced charge separation in a bismuth vanadate-silicon tandem photoelectrode. Nat Commun 2013:4

171. Dittrich T, Belaidi A, Ennaoui A (2011) Concepts of inorganic solid-state nanostructured solar cells. Sol Energy Mater 95(6):1527-1536

172. Du C, Yang XG, Mayer MT, Hoyt H, Xie J, McMahon G, Bischoping G, Wang DW (2013) Hematite-based water splitting with low turn-on voltages. Angew Chem Int Ed Engl 52(48): 12692-12695

173. Pasquarelli RM, Ginley DS, O’Hayre R (2011) Solution processing of transparent conductors: from flask to film. Chem Soc Rev 40(11):5406-5441 
174. Sodergren S, Hagfeldt A, Olsson J, Lindquist SE (1994) Theoretical-models for the action spectrum and the current-voltage characteristics of microporous semiconductor-films in photoelectrochemical cells. J Phys Chem 98(21):5552-5556

175. Hagfeldt A, Bjorksten U, Lindquist SE (1992) Photoelectrochemical studies of colloidal $\mathrm{TIO}_{2}$-films - the charge separation process studied by means of action spectra in the UV region. Sol Energy Mat Sol C 27(4):293-304

176. Bisquert J, Vikhrenko VS (2004) Interpretation of the time constants measured by kinetic techniques in nanostructured semiconductor electrodes and dye-sensitized solar cells. J Phys Chem B 108(7):2313-2322

177. Hagfeldt A, Lindstrom H, Sodergren S, Lindquist SE (1995) Photoelectrochemical studies of colloidal $\mathrm{TiO}_{2}$ films - the effect of oxygen studied by photocurrent transients. J Electroanal Chem 381(1-2):39-46

178. Abeles B, Sheng P, Coutts MD, Arie Y (1975) Structural and electrical properties of granular metal-films. Adv Phys 24(3):407-461

179. Terrill RH, Postlethwaite TA, Chen CH, Poon CD, Terzis A, Chen AD, Hutchison JE, Clark MR, Wignall G, Londono JD, Superfine R, Falvo M, Johnson CS, Samulski ET, Murray RW (1995) Monolayers in three dimensions: NMR, SAXS, thermal, and electron hopping studies of alkanethiol stabilized gold clusters. J Am Chem Soc 117(50):12537-12548

180. Yokoi T, Sakuma J, Maeda K, Domen K, Tatsumi T, Kondo JN (2011) Preparation of a colloidal array of $\mathrm{NaTaO}(3)$ nanoparticles via a confined space synthesis route and its photocatalytic application. Phys Chem Chem Phys 13(7):2563-2570

181. Townsend TK, Browning ND, Osterloh FE (2012) Nanoscale strontium titanate photocatalysts for overall water splitting. ACS Nano 6(8):7420-7426

182. Liu B, Wu C-H, Miao J, Yang P (2014) All inorganic semiconductor nanowire mesh for direct solar water splitting. ACS Nano 8(11):11739-11744

183. Liu J, Hisatomi T, Ma G, Iwanaga A, Minegishi T, Moriya Y, Katayama M, Kubota J, Domen $\mathrm{K}$ (2014) Improving the photoelectrochemical activity of $\mathrm{La}_{5} \mathrm{Ti}_{2} \mathrm{CuS}_{5} \mathrm{O}_{7}$ for hydrogen evolution by particle transfer and doping. Energy Environ Sci 7(7):2239-2242

184. Minegishi T, Nishimura N, Kubota J, Domen K (2013) Photoelectrochemical properties of $\mathrm{LaTiO}_{2} \mathrm{~N}$ electrodes prepared by particle transfer for sunlight-driven water splitting. Chem Sci 4(3):1120-1124

185. Urabe H, Hisatomi T, Minegishi T, Kubota J, Domen K (2014) Photoelectrochemical properties of $\mathrm{SrNbO} 2 \mathrm{~N}$ photoanodes for water oxidation fabricated by the particle transfer method. Faraday Discuss 176:213-223

186. Townsend TK, Sabio EM, Browning ND, Osterloh FE (2011) Improved niobate nanoscroll photocatalysts for partial water splitting. ChemSusChem 4(2):185-190

187. Kronik L, Shapira Y (1999) Surface photovoltage phenomena: theory, experiment, and applications. Surf Sci Rep 37:1-206

188. Kronik L, Shapira Y (2001) SPV review-short version. Surf Interface Anal 31:954-965

189. Zhao J, Osterloh FE (2014) Photochemical charge separation in nanocrystal photocatalyst films - insights from surface photovoltage spectroscopy. J Phys Chem Lett 5:782-786

190. Osterloh FE, Holmes MA, Zhao J, Chang L, Kawula S, Roehling JD, Moulé AJ (2014) P3HT: PCBM bulk-heterojunctions: observing interfacial and charge transfer states with surface photovoltage spectroscopy. J Phys Chem C 118(27):14723-14731

191. Osterloh FE, Holmes MA, Chang L, Moule AJ, Zhao J (2013) Photochemical charge separation in poly(3-hexylthiophene) (P3HT) films observed with surface photovoltage spectroscopy. J Phys Chem C 117(51):26905-26913

192. Lagowski J (1994) Semiconductor surface spectroscopies - the early years. Surf Sci 299 (1-3):92-101

193. Luria JL, Hoepker N, Bruce R, Jacobs AR, Groves C, Marohn JA (2012) Spectroscopic imaging of photopotentials and photoinduced potential fluctuations in a bulk heterojunction solar cell film. ACS Nano 6(11):9392-9401 
194. Burstein L, Bregman J, Shapira Y (1991) Characterization of interface states at III-V compound semiconductor-metal interfaces. J Appl Phys 69(4):2312-2316

195. Lagowski J, Jastrzebski L, Cullen GW (1981) Electronic characterization of hetero-epitaxial silicon-on-sapphire by surface photo-voltage spectroscopy. J Electrochem Soc 128(12): 2665-2670

196. Musser ME, Dahlberg SC (1980) The surface photo-voltage of polymethine semiconductingfilms. J Chem Phys 72(7):4084-4088

197. Moons E, Eschle M, Gratzel M (1997) Determination of the energy diagram of the dithioketopyrrolopyrrole/SnO2:F heterojunction by surface photovoltage spectroscopy. Appl Phys Lett 71(22):3305-3307

198. Gross D, Mora-Sero I, Dittrich T, Belaidi A, Mauser C, Houtepen AJ, Da Como E, Rogach AL, Feldmann J (2010) Charge separation in type II tunneling multi layered structures of CdTe and CdSe nanocrystals directly proven by surface photovoltage spectroscopy. J Am Chem Soc 132(17):5981

199. Dittrich T, Fiechter S, Thomas A (2011) Surface photovoltage spectroscopy of carbon nitride powder. Appl Phys Lett 99(8):084105-1-084105-3

200. Nowotny MK, Bogdanoff P, Dittrich T, Fiechter S, Fujishima A, Tributsch H (2010) Observations of p-type semiconductivity in titanium dioxide at room temperature. Mater Lett 64(8):928-930

201. Zidon Y, Shapira Y, Dittrich T, Otero L (2007) Light-induced charge separation in thin tetraphenyl-porphyrin layers deposited on Au. Phys Rev B 75(19)

202. Mandujano-Ramirez HJ, Gonzalez-Vazquez JP, Oskam G, Dittrich T, Garcia-Belmonte G, Mora-Sero I, Bisquert J, Anta JA (2014) Charge separation at disordered semiconductor heterojunctions from random walk numerical simulations. Phys Chem Chem Phys 16(9): 4082-4091

203. Fungo F, Milanesio ME, Durantini EN, Otero L, Dittrich T (2007) Optically induced switch of the surface work function in TiO2/porphyrin-C-60 dyad system. J Mater Chem 17(20): $2107-2112$

204. Herzog C, Belaidi A, Ogacho A, Dittrich T (2009) Inorganic solid state solar cell with ultrathin nanocomposite absorber based on nanoporous $\mathrm{TiO}(2)$ and $\operatorname{In}(2) \mathrm{S}(3)$. Energy Environ Sci 2(9):962-964

205. Maeda K, Mallouk TE (2009) Comparison of two- and three-layer restacked Dion-Jacobson phase niobate nanosheets as catalysts for photochemical hydrogen evolution. J Mater Chem 19(27):4813-4818

206. Compton OC, Osterloh FE (2009) Niobate nanosheets as catalysts for photochemical water splitting into hydrogen and hydrogen peroxide. J Phys Chem C 113(1):479-485

207. Lide DR (2008) Electron work function of the elements. In: CRC handbook of chemistry and physics, vol 88. CRC/Taylor and Francis, Boca Raton

208. Wang J, Osterloh FE (2014) Limiting factors for photochemical charge separation in $\mathrm{BiVO}_{4} /$ $\mathrm{Co}_{3} \mathrm{O}_{4}$, a highly active photocatalyst for water oxidation in sunlight. J Mater Chem A 2: 9405-9411

209. Kudo A, Ueda K, Kato H, Mikami I (1998) Photocatalytic O-2 evolution under visible light irradiation on $\mathrm{BiVO}_{4}$ in aqueous $\mathrm{AgNO}_{3}$ solution. Catal Lett 53(3-4):229-230 